\title{
Vicissitudes of laughter
}

\section{Managing interlocutor affiliation in talk about humanitarian aid}

\author{
Kevin McKenzie
}

This paper is concerned with the way that laughter is employed to manage threats to interlocutor affiliation in talk among humanitarian aid workers as they describe their professional activities in settings of armed conflict. I first set out to situate my analysis within the tradition of work in ethnomethodology and conversation analysis (EM), exploring how that approach differs in significant ways from work in pragmatics and related traditions of discourse analytic research. Unlike the latter approaches, EM examines laughter for the intelligibility it is deployed by speakers to furnish, so that the presumption of laughter's revelatory nature which characterizes a pragmatically-oriented analysis is seen as a participant resource for rendering the situated significance of actions visible by and for the involved parties of a given episode of interaction. Following this, I examine talk from open-ended interviews with aid agency operatives who work in Israel and the Palestinian Territories, exploring how laughter is employed to manage threats to interlocutor affiliation where the potential accusation of opportunism arises in accounts of personal job satisfaction as against the legitimacy otherwise afforded with an appeal to altruism and self-sacrifice. Where speakers attend to the criticism of humanitarian activity for its significance in affecting outcomes of warfare, the management of these different demands is accomplished in reflexive work to ironize their own and others' formulations of motivation for pursuing humanitarian work.

Keywords: accountability, armed conflict, ethnomethodology, Palestine/Israel, NGOs, humanitarian aid, laughter-in-interaction

\section{Introduction}

The purpose of this paper is to explore the role that laughter plays in managing the availability of different and competing demands for moral accountability in talk among humanitarian aid workers as they account for their professional activities in settings of armed conflict. I examine how speakers affiliate with one another in 
formulating accounts of their professional identity. More specifically, I consider how laughter features in talk where speakers account for their professional activities, and where the introduction of competing demands for moral accountability relating thereto threaten the appearance of mutual affiliation in the course of conversational interaction. As with talk in other settings, laughter features here as a way for speakers to identify and manage threats to the joint supposition of mutual reciprocity in perspective, both in regard to the intelligibility of the issues they discuss and to the status of their own contributions in the course of the related conversation (Glenn $2003,122-161)$. Of particular interest in the talk we will consider is a focus on the relationship between the ideational content invoked in motive accounts and the role of sequential repair work that laughter realizes as a way to "maintain mutually contradictory frames of interpretation" (Glenn 2003, 21, see also Mulkay 1988, 31-35). My point is not simply that laughter routinely features in talk about humanitarian work, nor that it obscures contradictory assumptions about the morality of such work; but that laughter is employed to broach alternative assumptions in and as its business of managing the extent of the relation each assumption has with its counterpart for an understanding of the morality of participant involvement in humanitarian activity. Morality is not the conditional precedent to that business, rather it is a means of formulating intelligibility. Its analysis requires distinguishing between how participants account for their professional identity and how they render accountable the production of their related explanations in and through the course of the accounts' production.

The analytic approach adopted in this paper is one that draws on and contributes to work in ethnomethodology and its related area of specialization, conversation analysis (hereafter EM). ${ }^{1}$ Work in this analytic tradition initially arose out of developments in sociology beginning with the founding research of Harold Garfinkel in the late 1950s and early 1960s (see Garfinkel 1974, 1991, 1996, 2002, 2006). While the importance of these developments are not unfamiliar to scholars working in discourse analytic and pragmatic traditions of research, there remains a great deal of misapprehension regarding EM's basic premises. In particular, EM is routinely criticized for being focused exclusively upon the details of turn-by-turn interaction to the neglect of more broadranging considerations having to do with the nature of institutional social structure and the place that individual agency has

1. Though the literature here is voluminous, pioneering work by the late Gail Jefferson (1979, 1984, 1985, Jefferson et al. 1987) is noteworthy for its significance in instigating the conversation analytic study of laughter. For an extensive discussion of Jefferson's contribution that seeks to extend her work, see the special memorial issue of Journal of Pragmatics $(42,1469-1576)$ entitled 'Laughter in Interaction,' edited by Johannes Wagner and Monika Vöge (2010). For some recent representative analyses of laughter in the conversation analytic tradition, see Edwards 2005; Haakana 2001, 2002; Holt 2010, 2011; Jefferson 2004; Lampert and Ervin-Tripp 2006. 
in relation to that structure (usually described in terms of micro vs. macro analysis, respectively). Such critique belies a fundamental failure to grasp the essential difference between how EM conceives of social order production and how more conventional approaches to sociological inquiry do so (Sharrock and Anderson 1987). In particular, it presumes the very conceptual distinction (between micro and macro orders of intelligibility) that EM examines for how its relevance is furnished in and as a part of the work of social order production itself. In other words, the micro vs. macro distinction that conventional approaches stipulate in order to make sense of the events and activities which they analyze is approached by EM as a resource - indeed, the fundamental resource (or method) - that participants themselves employ to render the significance of their own and others' situated activities intelligible (or accountable) in the course of interaction. The situated significance of social actors' developing activities are thus reflexively furnished as a constituent aspect of their unfolding conduct. This is no less so of professional sociological description than it is of the mundane formulation of explanation that takes place in settings of everyday talk. For EM, the significance of what participant activities exemplify (i.e., as the manifestation of macro structural entities they are taken to express at the micro level) is always and only ever the realization of social actors' own efforts to furnish them with the macro significance those activities are taken to have.

Social actors essentially provide for the macro theoretical relevance of their situated activities in the course of those activities' conduct, and it is in virtue of so theorizing the significance of their own and others' activities that those activities have the meanings they do, as instances of the macro structural forms they are taken, by those social actors, to exhibit. Social order is immanent to the very activities by which the macro order significance of situated activities is made relevant, and it is there - and only there - in the work of providing for that relevance, that social order is produced, in and as the concrete particulars of its phenomenal details. Thus, in EM's view, it is not the exogenous character of particular doings that render them with their situated significance, but the situated activity of regarding those particular doings as having such a character that renders their situated significance available. In other words, the transcendental character of particular doings resides exclusively in the circumstances where specific details are taken, by participants, to manifest some situation-external (or situation-transcendent) character. It is the activity of so-taking-them which constitutes the phenomenon of social order production - not the self-determining, reified structure whose ipso facto relevance is thus invoked in that situated activity. Remarking on this, Hilbert (2009, 172-173) notes: "the entire structural integrity of society, including whatever its members take to be factual reality (Hilbert 1992, 66-82), is ongoingly reproduced in ongoing behavior, not something external to the behavior which is causing it or making people experience it the way they do." 
It is the failure of conventional sociological analyses to distinguish between their own theory-laden efforts to account for what social actors do and social actors' similar, theory-laden efforts to render their activities accountable to one another that is shown up in EM references to the conflation of analyst and participant concerns. A result of this failure to distinguish between the concerns that participants pursue in the course of their interaction, and analysts' examination of how participants pursue those concerns means that the theoretical relevance of accountings which participants furnish in their own practices are seen as alternatives to those devised in the formulations that analysts of those practices seek to warrant in course of their own investigative research (Watson 1998). ${ }^{2}$ For this reason, Garfinkel refers to such second-order delineations with the term constructive (or formal) analysis (Garfinkel 1996; Garfinkel and Sacks 1970).

In this section, I will set about to explain the difference between EM and its constructive counterparts by way of examining some selected examples of discourse analytic and pragmatic research on laughter, after which I will then go on to present my own examination of how laughter is made to feature in talk about humanitarian aid. It should be noted from the outset, however, that exploring this distinction between EM and its more conventional counterparts is not directed at discrediting the mode of analysis those counterparts represent. Instead, it is directed at considering how the related conceptual understandings they work to develop are of essentially the same kind as those employed by the interactional participants themselves. Speaking to this point in relation to his own circle of professional colleagues, Hilbert $(2009,171)$ notes:

[S]ociologists can easily and unceasingly display the convincingness of macro-sociological matters, matters which, for them, ethnomethodologists simply "refuse" to recognize. Obviously, they say, there are large-scale institutional phenomena that ethnomethodologists refuse to recognize, and they can produce the evidence, and the evidence is astonishingly convincing. But somebody is doing that, is the ethnomethodological reply, and that somebody is: professional sociologists themselves. That they are doing it does not discredit the activity, and that they are doing it so well is what attracts Garfinkel's great admiration. But that they are doing it is a phenomenon in its own right, the phenomenon to which ethnomethodology directs our attention.

2. Note too that the rhetorical efficacy of such second-order analysis is dependent upon appropriating the categorical warrant furnished by the participants whose otherwise discredited sense-making it seeks to displace. In this way, the category entitlement that accrues to participant membership is paradoxically underwritten there (Sharrock 1974; Whalen and Zimmerman 1990), but only to the extent that it can be deployed for purposes of warranting claims that are inimical to the endogenously furnished terms of accountability they seek to replace. 
The implication that EM cashes out here is that there is no difference in principle between the mundane accounting that routinely takes place among lay social actors and professional sociologists. While they may, of course, employ different detailed methods in formulating their accounts (e.g., the use of statistical measures vs. the citation of evidential anecdotes, say), both professional analysts and lay social actors formulate explanations of situated activity in such a way that particulars are rendered intelligible (or visible) in relation to some set of interpretative categories, which categories, in turn, are rendered intelligible in relation to the particulars they assemble - a mutually elaborative relationship that Garfinkel (1967, 78), borrowing from Mannheim (1952), refers to with the gloss documentary method of interpretation. Garfinkel's contribution in all of this is to emphasize the reality of social order production (see Mehan and Wood 1975). That is, reality is by virtue of the fact that we take it to be, but it is no less real for all that. The very activity by which we methodically render some event or action with the significance it is (thereby) taken to have is, by definition, coordinative and therefore constitutive of social action. It is social reality par excellence. It is only the reifying, fetishizing work of constructive analysis that makes seeing this problematic because, as a feature of its own modus operandi, it assumes an ontological difference between representation and reality from the very outset. From an EM perspective, this loses sight of the very phenomenon of social order production since it depends upon a reifying gesture in the construction of its own analytic findings, disregarding how the situated production of just such findings features as endemic to the conduct of the social interaction in question. The use of laughter constitutes one means by which the participants to such interaction make their understandings available to each other, as the suppositional background which renders the occurrence of that laughter intelligible in the first place.

To put all of this somewhat differently still, as a fundamental axiom of conventional social science, the macro vs. micro distinction informs an approach to social order production in which the events of concrete circumstances are taken to be manifestations of institutional and/or cultural structures that transcend them (Winch 1958). The actual relationship between these different orders (the concrete micro and the transcendent macro) is, of course, the topic of much theoretical debate among professional sociological analysts; but the working assumption informing such debate is that the associated terms of reference denote ontologically distinct entities whose relationship it is the objective of scholarly undertakings to reveal. In contrast, for EM, social order is seen as an immanent accomplishment of the very efforts that are made relevant by participants to render their own and others' situated doings accountable within (or by means of) just such a transcendentalizing explanation. It is only in virtue of rendering situated activities 
intelligible as instances of some macro-order (which those activities are taken to manifest) that the meta- or trans-situational character of some situation-specific activity is itself established for and by the parties to a given encounter. ${ }^{3}$ Such a method of interpretation, wherein involved parties document the essentially immortal character which some situation-specific event is taken to manifest, is itself only ever available in a situation-specific activity wherein its relevance is furnished (Garfinkel 2002). This way of inverting the more conventional modes of understanding so as to incorporate the reflexive uses of their functioning in the circumstances where they occur is related to them as their asymmetrical alternative (Garfinkel and Wieder 1992). ${ }^{4}$

As one might suppose, this immanentist approach to social order production holds some profoundly significant implications for the analysis of face-to-face interaction. This is obvious, for instance, in how the issue of representativeness - as addressed to the question of how particular occurrences in interaction "typically" get employed - is respecified in EM for how that concern is made to feature in participants' own accounts. So, instead of inquiring about the degree to which some feature of interaction is typical, EM would instead consider how different ways of attending to that concern might be made to feature in the interaction under investigation. Note, this does not mean that EM ignores the question of representativeness. Rather, it means that EM's stance is one in which the only answer (to the question of representativeness) which could possibly matter is the one that participants provide, since it is they - and they alone - for whom the answer to such a question has any actual bearing on the situated circumstances where its relevance is furnished. Put conversely, it is only the significance that participants themselves give to the question of representativeness that can have any bearing on the conduct of affairs in the settings where it is furnished, since it is they who determine the relevance

3. This is not the same as asserting some trans-situational essence of situated social structure (Giddens 1984; Collins 1981, 1987; Wilson 2003). That is, it does not buy into the theoretical postulation of related assertions in order to appreciate how those assertions are rendered with their situated analytic purchase. Such a view is basically the same as that which EM seeks to respecify since it posits an order that is independent of the specific circumstances where that order's relevance is invoked (for related discussions, see Hilbert 2009 and McKenzie 2011).

4. Of this relationship, Garfinkel (1996: 10, col. I-II, italics in original) notes: "you can use ethnomethodology to recover ... the use of formal analytic practices. You can't do it the other way around. That is to say, you can't use the methods of formal analysis to recover the work and the findings that ethnomethodology is coming up with. (...) [T] hey are asymmetrically alternate, and that they are asymmetrically related is itself a social fact." 
of the answer in and for the course of that setting's unfolding development. ${ }^{5}$ The establishing of some turn's typicality features as participants' own practical business, attended to reflexively both in and as the conduct of their own unfolding interaction. It is the work of that transcendentalizing activity, whereby the immortal character of the social is furnished, which it is EM's concern to examine.

Note finally what all of this entails in terms of EM's own project: that the efficacy of some interactional device is regarded as uniquely adequate to the circumstances of its occurrence. Thus, it is not the case, say, that some speaker claim is effective because it gets deployed across a range of situations, but rather that its effectiveness is an internal determination of the situation-specific circumstances of its use a product or achievement of its unique adequacy in the specific circumstances where it is collaboratively "made to fly" (precisely by being treated as having a transcendent character that is conventional across a range of instances). It is in the situated activity where that business is pursued - and only in such activity - that social order gets produced as an immanent accomplishment of the sense-making by which the significance of those activities are reflexively made visible to and for the participants in the particular setting in question (Garfinkel 1967, 75; Mair et al. 2015). Think of it this way: if an episode of interaction has some particular shape which the status of its constitutive contributions give it, it is that way because those contributions are treated as having that status by the participant members of the interaction in question.

EM's disciplinary stance here is one involving the principled insistence on examining exactly where and how the relevance of typicality is operative in the immanent production of social order (Schegloff 1997; Potter 1998). Any claim concerning the meta- or trans-situational relevance of an account is necessarily constructive, whether the claim be made by participants or by others (analysts) who are not party to the settings in question. ${ }^{6}$ Let us be clear here: EM's own claims that, say, some device is employed methodically across a range of different instances is also, of course, itself an assertion warranted with its own methods of invoking evidence and the like (such as that involving the use of audio-recordings and

5. Of course, such answers can take the form of explicit formulations (for example, as a way to underwrite the credibility of independent claims), or they can get furnished inferentially in the uptake whereby an interlocutor displays his or her understanding of an immediately prior turn's significance (so that whether some prior contribution is or is not regarded as typical - that is, conventional - is displayed in and through the response which that contribution occasions, see Hutchby and Wooffit 2008).

6. The difference, of course, is that the relevance of the former is endogenous to the circumstances where it is reflexively furnished, while in the case of the latter, this is not so. 
related conversational transcripts, cf. Ashmore and Reed 2000). Yet, the fact that EM employs just such methods to warrant its claims does not undermine its point about the unique adequacy of such situated methods. On the contrary, it stands as a demonstration of that very point in the substantiation of its own constructive assertions (cf. Ashmore 1989). Put more simply, if every instance is unique, then the-claim-that-every-instance-is-unique is itself unique, on each and every occasion where it is made - not simply despite the apparent contradiction this involves (since the reference to "each occasion where it is made" asserts some commonality that transcends any of those unique occasions), but as a realized expression of that assertion itself. Such assertions on EM's part differ from those of its formal analytic counterparts not in the fact that they are about whether the device some participant deploys has a trans-situational, conventional status, but rather in the fact that on the specific occasion under scrutiny, that device is taken by participants to have just such a status.

When we turn to the specifics involved in a comparative analysis of laughter, what all of this means is that EM's approach is necessarily incommensurable with that of the constructive projects that seek to examine discursive interaction for what it can tell us about the putatively underlying causes of laughter (Garfinkel 2007). For instance, in one well-established tradition of inquiry that approaches laughter from the perspective of humor, one begins from the foundational assumption that laughter demonstrates an individual's awareness of contradictory ways of thinking that are manifested in various settings of talk. From this perspective, laughter is seen as the outward evidence of discrete inner psychological processes registering the notional incongruity emergent in different settings (Bergson et al. 1914; Koestler 1964). What it is that makes something laughable is thus seen as having its origin in some domain of meaning which precedes the related laughter, and to which that laughter is responsive. Similarly, work in various social psychological and psychoanalytic traditions seeks to explain laugher as the result of machinations which take place in some inner mental domain. Glenn (2003) outlines some major areas of related work here, categorizing these in relation to four basic theories on the origin of laughter: (1) superiority/hostility theory, where laughter is said to have developed as an expression of revelry against an enemy, (2) incongruity theory, in which laughter is seen as a response to cognitive dissonance, (3) relief theory, in which laughter is regarded as an expression of release from psychological tension, and (4) Freudian/ psychoanalytic theories which regard laughter as a means to sustain the optimal level of psychic arousal (cf. Freud 1938). ${ }^{7}$ More recent work, including that in the tradition of critical discourse analysis, similarly approaches laughter as indicative

7. For how these theories of laughter have been developed in related bodies of research, see Glenn 2003, 7-34; Chapman and Foot 1976; Billig 2005. 
of autonomous (social, cognitive or linguistic-structural) phenomena (see Holmes 2002, 2006; Holmes and Marra 2002; Keyton and Beck 2010). ${ }^{8}$

What these and related lines of inquiry have in common is an approach to laughter which sees it as a heuristic for the exploration of something which that laughter is taken to index. That is, in pursuing the very question of laughter's underlying causes, such approaches lose sight of how that question's relevance is furnished by participants themselves in and as a part of the rather complex business they undertake to account for their own situated doings. In other words, the very modes of reasoning that these conventional analyses of laugher deploy are essentially the same as those that are invoked in and through participants' own use of laughter. Seen in this way, laughter is not what is in need of an account. Rather, laughter furnishes the occasion for the inferential formulation of an account on the part of those who are involved in its production. For participants, it is laughter that begs the question of its source (or cause) and, in so doing, occasions the relevance of answers that relate (either by way of ratification or discrediting) to a shared understanding of what is going on in the setting where that laughter occurs. For EM, laughter is thus not seen to be the result of things like threats to face, cognitive dissonance, relative differences in institutional and social power, etc. Instead, laughter is seen as a way to invoke the relevance of the suppositions that these and related accounts furnish. In attempting to answer these questions as part of its own analytic remit, constructive approaches overlook how it is that posing the relevance of such questions (by means of laughter) contributes to the business of rendering the intelligibility of the related activities visible in and through the course of the encounter itself, as a reflexively pervasive feature of its conduct, endemically constitutive of the course of events that make up the encounter's unfolding development (Boden 1990).

The logical calculus that situates laughter as an outcome of (rather than the occasion for) inferring the causal relations that get implicated with its use is formulated in the voluminous literature relating a pragmatics of humor to social power, cognition, etc. It is quite beyond the scope of this paper to furnish a comprehensive overview of that literature (for examples of which, see Attardo 1997, 2002; RuizGurillo and Alvarado-Ortega 2013); but for purposes of clarifying exactly how EM differs from the associated endeavors, I want to consider the details of a few selected examples of related work in order to tease out the implications that the different investigative approaches bring to their respective tasks. As we shall see, these examples do not simply represent alternative analytic contributions to a wider

8. These three kinds of derivative or reductionist accounting, involving (1) structure, (2) agency (intention, hidden cognition, etc.), and (3) the reification of discursive form are explicitly referred to in van Dijk's (1998) eclectic formulation (though see van Dijk 2006 for an attempt to elaborate the first mode in terms of the second). 
corpus of empirical findings - as if EM itself constituted a distinct but conceptually undifferentiated way of arriving at insights into social order and discursive interaction. Rather, they constitute work that is fundamentally incommensurable with EM in the way they conceive of laughter in the first place. My examination of the examples from this literature, though necessarily limited in scope, will focus on the essential difference between EM and these more conventional approaches; and will, I hope, suffice to clarify the radical implications for an understanding of interaction posed by EM's own unique analytic perspective.

\subsection{Warranting categorical analysis}

Let us start by considering a piece of research carried out by Joann Keyton and Stephenson Beck (2010) directed at examining laughter in jury deliberations. I have chosen to begin with this particular example as a comparative point of reference primarily because it is redolent of work carried out by Harold Garfinkel in his own classic, seminal research in ethnomethodology (1967: 104-115; see also Heritage 1984: 4-5). In that work, Garfinkel describes how the explanations that jury members formulate to account for their decisions entail their invoking various norms of reasoning in order to justify their decisions. That is, jury members routinely make their deliberative contributions answerable to normative considerations which they invoke in and through the course of proceedings. By making their decisions answerable to suppositions about what constitutes adequate reasoning, members not only display to and for one another that they are acting competently in their capacity as jurors, but simultaneously show what it is that they regard the appropriate conduct of such a role to be. Put more simply, in the reflexively apposite display they make of their own conduct, they bring their activities off as the very actions pertinent to a jury's deliberative work. Garfinkel showed that members make their contributions visible to one another as just the sort of collaborative activities whose normative conformity embodies the proficient work of a jury's deliberative undertakings.

By way of contrast, the investigation that Keyton and Beck carry out is one that overlooks this reflexive feature of interaction. This is especially relevant for their examination of laughter because it means that they regard laughter's occurrence as an intrusion upon the interactional business which it is the task of the jury to carry out. This contrasts markedly with how EM approaches laughter in that for the latter, the constituent details of a given occasion are examined for how they contribute to the interactional work that gets carried out in that setting. Laughter, like the reflexively-oriented explanations that jury members formulate to account for their decisions, is thus regarded as a means by which the pursuit of the interaction's objectives are rendered visible as just the sort of things they are taken by members 
to be. To put it less formally, interaction wears its meaning on its sleeve. Each detail of an interaction's conduct refers to its own significance in carrying off the business of the encounter to which it is a constituent contribution. In that laughter is one such constituent in the encounters that Keyton and Beck consider, their treatment of its occurrence as somehow epiphenomenal to the business conducted there is one that disregards the essentially reflexive nature of situated action (though, as we shall see below, they do acknowledge its conceptual relevance, even while excluding it as a formal property of their analysis).

Let us consider the details of what this involves. From the very outset of their article, Keyton and Beck begin by describing a particular case in which jury members are mandated to decide the guilt or innocence of a defendant on the charges of murder. Noting the potential implications which that decision has on the punitive outcomes of the verdict (viz., whether the defendant is to be executed or incarcerated, and in the latter case, under what terms), Keaton and Beck highlight the need for jury members to arrive at a reciprocal understanding in order successfully to carry out their collaborative undertaking. Here, Keyton and Beck propose that laughter be seen as an intrusive element in the deliberative proceedings - one which threatens a potentially catastrophic and irreversible miscarriage of justice - and that, as such, it is a factor which needs to be eliminated if a jury's interactional business is to be successfully carried out. This contrasts markedly with the perspective of EM, where laughter is examined for how it routinely contributes to the successful pursuit of interlocutors' interactional business. From this perspective, it is precisely by identifying and foreclosing the potential misapprehensions which otherwise threaten the successful conduct of their deliberations that jury members effectively accomplish the profoundly consequential outcomes which Keyton and Beck presume laughter threatens. More specifically, it is through means of their laughter that interlocutors carry out the conversational reparative work which establishes the suppositional grounds of their mutual orientation - precisely the objective that Keaton and Beck champion in support of their own proscriptive approach to laughter. By treating laughter as a hindrance to the jury's deliberative work, Keyton and Beck not only overlook its significance in effecting that work, but would seemingly wish to deny jurors one of their key resources for the effective pursuit of their common objective.

Further, in their descriptions of what occurs in the deliberative proceedings they examine, Keyton and Beck's treat laughter in such a way as to underwrite their own independent postulation of a set of categorical functions which are said to describe the proper conduct of the deliberative undertaking ("organized by relational, procedural, and informational themes", p. 395), and which are implicitly suggestive of recommendations for remedial intervention. As an example of one such operation, Keaton and Beck reproduce the following extract documenting talk where jury 
members discuss the punitive outcomes of the alternative verdicts they consider. Keyton and Beck regard laughter here to be the source of "procedural error" (p. 398):

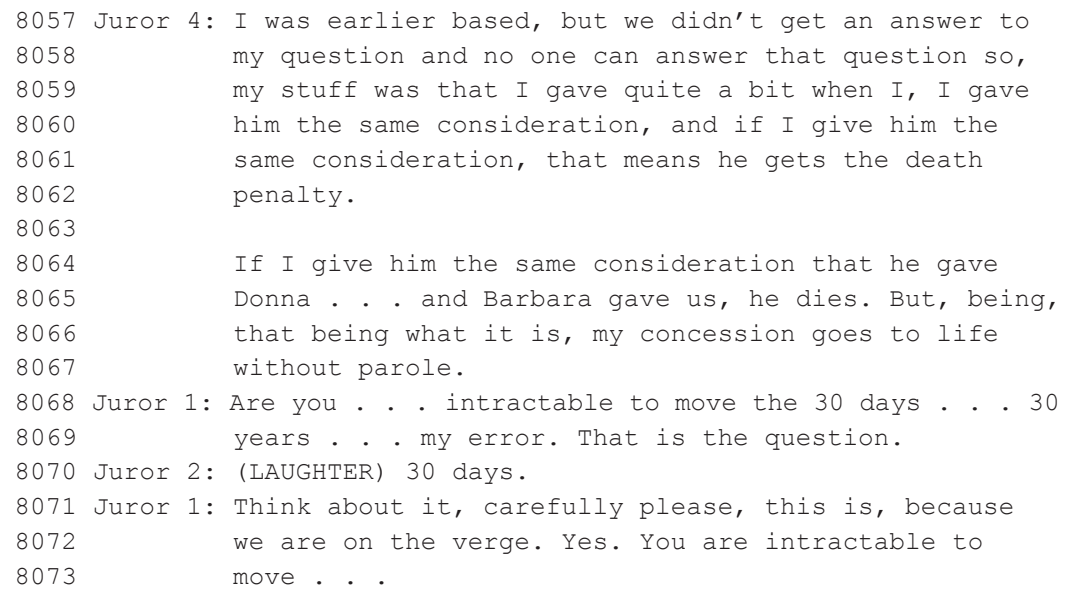

Remarking in general upon the sort of deliberations represented in this extract, Keyton and Beck note (ibid.: 399, italics in original):

Both signaling procedural error and signaling off topic demonstrated how laughter renders a jury temporarily ineffective. In other words, in these cases and others (signaling confusion, marking inappropriate use of informality, error recognition, no control in conversation), laughter is an indication that the jury is not performing their central task of discussion and decision making. But laughter as a processual function could also be beneficial as in the instance in which laughter delineates or affirms a procedural move made by another juror.

Keyton and Beck's assessment of the business that takes place here interprets it in relation to the various functions with which the related talk conforms to the categories proposed in their own system of classification; and because they dissociate laughter from the adjudicative purposes these particular jurors are mandated to pursue, the identification of potentially disparate assumptions regarding the punitive consequences of their verdict (here specifically, having to do with the length of incarceration incumbent to a particular finding, lines 8068-8070) is seen as an intrusion upon the otherwise trouble-free conduct of the procedural undertakings that constitute the jury's shared undertaking. It it as if the task of formulating a jointly ratified decision of such grave consequence were simply incompatible with the apparent levity by means of which that undertaking is carried out. Even where they do make passing note of how laughter contributes to advancing participants' collaborative work (in the final sentence of the remarks quoted above), such participant efforts are interpreted exclusively for their relevance in underwriting the 
categorical model of interactional function that Keyton and Beck construct ("laughter as a processual function could also be beneficial ... [where] laughter delineates or affirms a procedural move").

By way of contrast, EM would approach laughter for how it features as a way to manage potential troubles in the talk, rather than a source of just such trouble. More specifically, it would regard laughter as the means by which participants indicate to one another the potential disparities in the presumptive grounding that they jointly suppose informs the mutual understanding of what it is they are engaged in doing. In relation to the specific details of talk here, laughter constitutes the uptake with which one speaker (Juror 2, line 8070) displays to and for the immediately-prior speaker (Juror 1, lines 8068-8069) what s/he takes the potential disparity in understanding to be (viz., that relating to the length of time to be served prior to eligibility for parole), with subsequent uptake (Juror 1, lines 8071-8073) confirming the upshot of that prior reading in a next-turn. Thus, the disparity in what the speakers take one another's respective contributions to signify is not the outcome of the laughter in question, but is the trouble which is anticipated and foreclosed through the deployment of laughter at just the conversational juncture where the potential source of confusion is taken, by the participants, to occur. It is the very retrospective postulation of divergent understandings that laughter implicates and which serves as the means by which such anticipatory work is accomplished. Keaton and Beck are, of course, quite right to see the laughter in this exchange as having something to do with trouble arising in the management of procedural business. However, by regarding laughter as the cause of that trouble, they overlook how laughter provides for the relevance of alternative ways of understanding as the means of disambiguation. They essentially confuse the participant management of procedural trouble with the potential for error that such interactional work is itself designed to preclude. All of this is because Keyton and Beck treat the details of talk as different from the order of affairs which those details essentially realize. For instance, where elsewhere they refer to "emotion" and "group dynamics" in their account of laughter (p. 390), they also likewise construe these as ontologically different from the conversational activity they invoke such terms to explain. All of this could of course be taken as a simple case of careless description. Yet, Keyton and Beck themselves make a point of criticizing EM for what they claim is its failure to provide an adequate definition of laughter (ibid.: 388, citing Truong and van Leeuwen 2007), insinuating that their own therapeutic diagnostics afford greater insight into the conduct of the jury's deliberative business than EM's examination of how members' methods achieve those outcomes. In this way, Keyton and Beck confound the presumed warrant of their own analytic endeavor with the conceptual propriety they take to underwrite its related claims. 


\subsection{Structure and agency as explanatory devices in the pragmatic analysis of laughter}

The analytic orientation we considered above was directed at warranting a remedial stance towards foreclosing the catastrophic eventualities that would potentially result from a jury's failure properly to carry out its mandate. What is interesting about this approach is that it presumes to know better than those social actors themselves what their own business is. It also presumes that the analytic findings it discloses are more-or-less directly pertinent for remedial intervention - again, on the same assumption that analysts know better how to conduct the jury's task of carrying out its deliberative business than does the jury itself. Such an analysis induces from the suppositions it brings to its investigation exactly how those deliberations are or are not rendered effective. Put more simply, it judges the efficacy of members' undertakings, not on the basis of considering how the details of interaction contribute to the conduct of that business, but on the presupposition concerning laughter's status which it brings to the analytic task from the outset (cf. Hutchinson et al. 2008). By beginning with the assumption that laughter is epiphenomenal to the order of affairs where it occurs, such analysis ends up losing sight of the very phenomenon of how that laughter, to a great extent and in an essential way, realizes the order of affairs to which it is a contribution (Garfinkel 2002). ${ }^{9}$

A range of other work in the investigative tradition of pragmatically-informed discourse analysis similarly loses sight of the phenomenon of situated order production in the way that it treats laughter as symptomatic of underlying societal relations and/or psychological processes whose explanatory relevance that laughter is taken to belie. Perhaps more tendentiously, the reflexive work that laughter is employed by participants to accomplish in providing for the intelligibility of their situated activities is expropriated in these second-order analyses to account for laughter in much the same terms which that laughter is itself employed by participants to implicate. This is especially so where laughter is regarded as expressive of efforts on the part of interlocutors to avoid the very explanations it is employed by those same interlocutors to make relevant. That is, in talk where speakers employ laughter to preclude the appurtenance of otherwise inferentially fecund explanations, second

9. Of course, this disregard is not, strictly speaking, considered by EM to be a failure on its part, since what it is that analysts like Keyton and Beck set out to do with their research is not the same thing as that which EM sets out to do with its own investigations. Instead, EM would regard Keyton and Beck's treatment of laughter as essential to furnishing the warrant for their own implicit claims of remedial intervention in the conduct of jury deliberations. If the justification for Keyton and Beck's analysis lies in the implications it suggests for improvement to the conduct of jury deliberations, then a formal distinction between the discursive structure that such deliberations exhibit, on the one hand, and laughter as an intrusion upon that structure, on the other, is essential to the intelligibility of that justification. 
order analysts regard such efforts as corroborating evidence that substantiates the very reading which that laughter is designed to circumscribe. What all of this means is that certain discourse analytic and pragmatic analyses of laughter are distinguished from the actual uses which laughter is deployed to accomplish in their oversight of how laughter can be employed to foreclose or impede the accounts it otherwise evinces. In other words, laughter can be used to rule out the very understandings it makes relevant, and because contrasting analyses in pragmatics seek to account for laughter as the causal outcome (or resulting consequence) of the suppositions that speakers make relevant through its use, such analyses are then faced with the methodological problem of resolving the mutually exclusive nature of the alternative presumptions which the varied uses of laughter implicate. So, for example, in her review of how laughter is treated in Speech Act theory, Janet Holmes (2000) considers Paddy Austin's (1990) effort to uncover an overlooked aspect of politeness theory in which repressive societal relations are said to be obscured through humorous effect, comparing this with analytic work which regards laughter as oriented to managing "negative and positive face needs" (citing Brown and Levinson 1987). Here, Austin is said to introduce a complicating aspect of asymmetrical societal relations to an otherwise relatively straightforward analysis of face management, such that the significance of laughter conceived in the tradition of Brown and Levinson's approach is regarded as inadequate for a complete rendering of what takes place in the talk.

Note that the resulting enigma relating to what Austin calls the "dark side of politeness" arises precisely because the alternative explanations laughter is taken to implicate are presumed, as an initial postulate of the analysis, to be the cause of its occurrence. The predicament involved here is thus not the speakers' practical problem of providing for the interpretative relevance of the related suppositions which laughter invokes, but rather an analyst's problem of conceptual coherence (or non-contradictoriness in explanation). In other words, because both "positive and negative face needs", on the one hand, and societal coercion, on the other, are taken by constructive analysts to be the causal sources of laughter; the variable nature of the accounts which the related speaker explanations furnish end up posing a methodological conundrum for such second-order investigations. Here is how Holmes (ibid.: 165) describes the matter (in related analyses where laughter is treated specifically as an expression of humour):

Humour is ... a very effective way of 'doing power' less explicitly, and hence some uses of humour are more illuminatingly analysed as instances of coercive or repressive discourse. In other words, humour can be used to achieve the speaker's instrumental goal [of coercing others] while apparently de-emphasizing the power differential [between them]. Pizzini (1991: 477) for example, describes how gynaecologists used humour to 'move interview talk along' and 'to stop patients rambling on' in order to gain patients' compliance with their agenda. An analysis which treats such humour as simply attenuating an FTA [face threatening act], i.e. 
as purely an expression of concern for the addressee's face, risks under-analysing the interactional social significance of the exchange, and ignoring the complexity of the communicative goals involved (see Tracy and Coupland, 1990).

Conversely, humour can also be used by the subordinate in an unequal power relationship to subvert the overt power structure. Humour provides a socially acceptable means of signaling lack of agreement, registering a protest, or even a challenge to more powerful participants. Graham et al. (1992: 162) comment on this use of humour to 'veil socially unacceptable behaviour'; and Winick (1976) and Pizzini both comment on the fact that humour enables subordinates to express risky opinions.

Otherwise disparate analytic suppositions about the nature of laughter get drawn upon here, with the result that it is unclear in Holmes' description how the "communicative goals" (i.e., intention) she refers to are either mediated by relations of social power or are instead productive of those relations. Both individual intention and societal constraint are invoked to account for laughter, where that laughter is regarded to be an outward manifestation of otherwise hidden machinations. ${ }^{10}$ The powerless are said to resist dominance, while simultaneously obscuring their own efforts to do so. At the same time, social power is said to enable the dominance of particular speakers precisely in and through the effects of humor in "de-emphasizing" its operation. Here, power is described as functioning in a way that is determinative yet subverted, dominant yet undermined.

An alternative to this way of approaching this matter would be to consider how participants selectively and variably deploy different, otherwise competing explanatory resources in the formulation of their own accounts (see Billig et al. 1988). Seen from this perspective, the analysis would consider how different suppositions are variably invoked with laughter, and how, if at all, the contradiction between competing assumptions is mitigated by the participants themselves. In the case of the discrete explanatory relevancies that Holmes considers here, such an approach would investigate whether interlocutors display to one another that they regard asymmetries of power to be in play; and if not, then how is that supposition furnished. Here, the significance of asymmetrical power is such that laughter's work in attending to its relevance is ambivalent. That is, whatever power relations exist between speakers does not determine those speakers' orientation to one another,

10. For instance, consider how the description of doctor-patient interaction is formulated here. It is as if the doctor's "gain[ing of] compliance with the [diagnostic] agenda" were somehow different from or at odds with the corraborative work that doctors and patients undertake to furnish the warrant for the physician's relative expertise (see Heritage 2004; Horton-Salway 1998; Maynard and Heritage 2005; Schegloff 1992; Strengers 2011: 175-176). This is to counterpose the asymmetries in the warrantability of doctors' diagnostic claims with the collaboratively achieved, interactional work carried out to underwrite it. It is to confuse the supposition of privileged medical expertise jointly furnished by the various parties to the talk with asymmetries in the collaboration of its situated production. 
nor indeed does it precede the encounter where its relevance is furnished. Rather, the institutional nature of asymmetrical rights, responsibilities, privileges, etc. in an encounter are a collaborative accomplishment (Foucault 1980; Rawls' introduction to Garfinkel 2002: 56). That is necessarily and essentially ambivalent, and the work of laughter on this account is to manage the threat to the shared assumption of reciprocity in perspective which the collaborative work of providing for the variably distributed rights and responsibilities in a given encounter involves. That variability does not account for the laughter; rather, the laughter accounts for the variability (or ambivalence) in the suppositions that participants are oriented to in their talk. This aspect of situated interaction is registered, of course, in the analytic treatments that Holmes reviews; but because they regard laughter as the effect of the suppositions which participants employ laughter variably to furnish, those second-order accounts are unable to come to terms with the suppositional ambivalence that participants routinely employ their laughter to manage.

All of this might seem to suggest a concession to a second-order analytic approach which assumes that power is hidden from view, yet the point is that making that very assumption relevant is precisely what the laughter itself accomplishes. Through laughter's deployment, participants invoke a supposition whose particular content is otherwise unspecified (but whose relevance the laughter furnishes). The very concealment (or hidden-ness) of that to which speakers refer is achieved in the intimation of disclosure that laughter provides. Laughter's broaching of a potential disparity in ways of understanding is the means by which the relevance of such alternatives is made available. The work that pragmatic analyses do to account for laughter as the variable expression of disparate presumptive concerns is work that participants themselves undertake in and through their use of laughter. ${ }^{11}$ What is so fascinating here is precisely how laughter poses the autonomy of its obliquely referred-to domain - that is, laughter posits its target as the independent grounds to its own act of referral. Furthermore, the specific propositional content of a threat to reciprocity need not even be detailed in order for the referential work to be realized. ${ }^{12}$

11. Žižek (2011: 302) addresses this same point in comments regarding the phenomenology of understanding: "We should introduce here a precise distinction between the presupposed/shadowy part of what appear as ontic objects and the ontological horizon of their appearing. On the one hand, as it was brilliantly developed by Edmund Husserl in his phenomenological analysis of perceptions, every perception even of an ordinary object, involves a series of assumptions about its unseen flip side, as well as of its background; on the other hand, an object always appears within a certain horizon of hermeneutic prejudices that provide an a priori frame within which we locate this object and which thus make the object intelligible - to observe reality without prejudices means to understand nothing."

12. Indeed, as Holmes herself suggests, the non-specificity of reference is conducive to laughter's efficacy. 
In this way, interlocutors sustain the shared assumption that they see things in the same way by introducing the possibility of there being a way-of-seeing that is an alternative to the way-of-seeing which they take themselves to be sustaining.

Attending to the ambivalent nature of axiomatic assumptions that interlocutors orient to in their joint furnishing of institutional rights and responsibilities is a reflexive aspect of laughter's routine deployment in workplace settings. It constitutes participants' own situated business. Analysis which sets out to make its own sense of laughter instead of considering the reflexive sense-making that laughter is employed by participants to accomplish ends up employing equally ambivalent descriptions as those employed by the speakers whose laughter it examines. Thus, to return to Holmes' remarks quoted above, if humor were to "veil socially unacceptable behaviour", then it would be a mystery as to how such veiling would be evident to those both by and for whom it is made relevant. Put differently, how would it be possible for members to obscure anything (motive, hierarchical social relations, etc.) unless their concealment of that thing were, by virtue of their related actions, evocative of that to which it refers? What conventional analyses miss here is that the "socially unacceptable behaviour" that is being "veiled" is such that its concealment is made relevant precisely as obfuscation, as a touching-upon or skirting-around of what is not said directly. The work conducted by participants with their laughter is that of providing for the ambivalent character of the disparate suppositions to which they attend in the immediate setting. It is not that one supposition is privileged at the expense of its (obscured or hidden) alternative, but that the alternatives are ambivalently furnished. Such is the paradoxical nature of sense-making. The indirect reference involved where otherwise incompatible suppositions are at stake relates to laughter's work of managing the potential breakdown in reciprocity of perspective. That management occurs where laughter's announcement that there exists a threat to reciprocity presumes the possibility of a common perspective that can be broached in the first place (Pollner 1974, 1987).

Let us consider just one further example of how a conventional pragmatic approach operates, drawing again on Holmes' (2000) analysis of talk in an office workplace (represented as Extract 9, p. 172):

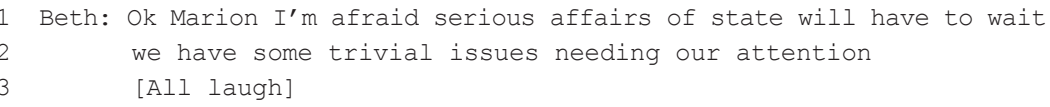

There are several indications that this utterance is motivated by politeness and oriented to the addressee's negative face needs: the use of the pronouns 'we' and 'our', for instance, function to align the manager [Beth] and the administrative assistant [Marion], expressing positive politeness and solidarity; and the source of the humour itself - the ironic downgrading of their on-task work to 'trivial' compared to 
the social talk or work gossip in which the two women [Marion and the secretary with whom she was speaking] were engaged - also serves this purpose.

Excerpt 9 is also a classic case of competing discourses (Lee, 1992) - this time involving those of solidarity and power. The utterance reflects Beth's competing loyalties - to Marion as a colleague, on the one hand, and, on the other, to the management team which requires that she move Marion back on task. Hence, at one level Excerpt 9 illustrates the use of humour to maintain good relations between those with differential power, and to avoid the overt enactment of power or authority. But it is also possible to interpret such interactions as instances of repressive discourse, where humour is co-opted for less positive purposes. In power-differentiated contexts, humour can be regarded as a discourse strategy which disguises oppression - a device to sugar the [metaphorical] pill [of repressive coercion].

Consider Holmes' claim here that asymmetries in power account for what takes place in the talk. Holmes first acknowledging that speakers foreclose the potential for the joint tasking of their workplace activities to be construed as coercively manipulated (in her analysis of the laughter as oriented to the management of face needs). She then goes on, by invoking the supposition of asymmetrical power and coercion, to corroborate the very apprehensions those participant efforts are designed to head off. It is as if in order to make those participant efforts visible in her analysis, she must deploy the very assumptions those same efforts are designed to controvert. So while it is the case that speakers treat hierarchical structure as if it preceded and were therefore independent of their efforts to endow it with its situated relevance, Holmes' oversight here is to buy into this reificatory gesture, overlooking how the related formulation is itself reflexively oriented to accomplishing the suspension of demands for accountability that the alternative assumption of cooperativeness simultaneously bodes.

It is clear that conventional pragmatic analysis acknowledges the contradictory nature of accountability, if for no other reason than that it highlights alternative ways of analysing laughter. However, because of its predilection for disambiguity, it neglects to consider how managing the parameters of interpretative ambivalence constitutes the primary business that speakers attend to with their laughter. Instead, it treats the management of that business as if it had taken place despite laughter's relation to the talk where it occurs. By treating the laughter as "co-opted for less positive purposes ... [and] as a discourse strategy which disguises oppression", this disregards how the work of co-option is reflexively furnished by participants as their own joint accomplishment. ${ }^{13}$ It is that situated treatment by participants (in which the potential to regard their workplace co-operation as coerced is itself

13. This is to treat speakers as the pawns (or dopes) of the reified structures whose relevance those speakers posit in the first place (Garfinkel 1967, 66-75; Lynch 2012). 
foreclosed with laughter) where asymmetrical power is made relevant in the first place. Thus, laughter does not "disguise" oppression. It provides for its possibility in and through the very display it enacts to dismiss its relevance. Put differently, laughter is a resource that speakers employ to produce the status of its referent (or target) as laughable. Laughter is regarded as a means by which speakers imbue its ostensible referents with the status they have, and though that status may be the subject of further and ongoing negotiation in the course of talk's development, it is in and through the use of laughter that some referent comes to have the (laughable) status that it does. Laughter is thus seen as productive of (rather than responsive to) the character of its referents. Even though speakers construe the target of their laughter to be its cause (or source), it is that very act of construal which is productive of that target's status (Heidegger 1993; Ashmore et al. 2004). ${ }^{14}$

As related to the specific concern of this paper with mundane explanations of humanitarian aid, we will see that the productive work of laughter is integral to speakers' efforts to render their own and others' professional activities accountable to disparate and conflicting moral assumptions. Just as in circumstances whose institutional role and individual autonomy pose the need to manage the disparate relevance of related suppositions; so too in the talk we will consider below, laughter features as a way for speakers to identify and repair potential breakdowns in the shared assumption of mutual reciprocity which the invocation of contrasting moral assumptions otherwise poses for the joint production of a shared account. Not only is laughter employed to treat those disparate assumptions as incompatible (and thus potentially troublesome to speaker affiliation), but it also furnishes alternative grounds for continued speaker affiliation in and through the mutual recognition of the trouble that the related laughter broaches.

\section{Background}

The talk that we will consider below was recorded in a series of open-ended interviews with representatives of various non-governmental organizations and human rights advocacy groups that operate in Israel and the Occupied Palestinian

14. Referred to by Garfinkel (2002, who borrows from Schütz 1967) with the term natural attitude, this aspect of talk involves the routine construal of the world as external to and independent of the referential gestures by which meaning is rendered available in a specific setting (for related discussion, see also Sharrock 2004). Note here that Garfinkel does not seek to deny the reality of that to which speakers refer, but to re-specify the questions of social ontology in terms of what is immanently accomplished in and through members' methodical practices (see Garfinkel 1974). 
Territories. ${ }^{15}$ My concern in recording these encounters was to explore how the professional identity of humanitarian aid is constructed in mundane explanatory accounts, and to examine what concerns speakers attend to in discussing the role that the organizations they represent may (or may not) play in effecting the conflicts where they operate. This issue concerning the legitimacy of humanitarian aid is the topic of an extensive and ongoing debate carried out in both the scholarly and professional practitioner literature, with participants addressing the potential conflict between the demand for non-partisanship on the one hand, and the alleviation of human suffering attending conditions of warfare on the other (Jha and Hobsbawm 2006; Kaldor 1999; Malešević 2010; McKenzie 2009; Steiner and Alston $2000,323-402)$. A poignant issue in all of this is the potential encroachment of either of these demands upon its opposite, such that a commitment to non-partisanship is potentially seen as negligent of the conditions necessary for the identification of aid recipiency, while aid delivery is potentially seen to involve a commitment to the partisan interests of aid recipients. These dual concerns attend to the moral legitimacy of humanitarian work, raising the questions of what ethical imperatives are legitimately served with humanitarian aid, and the relationship, if any, that such work has with the events of armed conflict (Rieff 2002). In talk about the work of humanitarian aid, speakers make themselves answerable to diverse and sometimes conflicting assumptions about the legitimacy of their professional activities.

In terms of how this all relates to the study of laughter, we will see that laughter and certain laugh-like features of talk furnish the means by which speakers manage the relevance of otherwise inexplicit or unspecified demands for moral accountability. Note that the claim here regarding these demands is not that they are obscured during the course of talk, or that they must somehow be divined in a context where laughter is regarded as an opaque medium that belies the otherwise hidden significance of a laughable. Rather it is the more straightforward point that it is in and through the deployment of laughter (and laugh-like features) that the relevance of these assumptions is made conspicuous in the course of talk's production. Here, a

15. These analytic materials are part of a dataset collected during my tenure as Visiting Research Scholar at the University of Cyprus in the Spring of 2004, being comprised of audio recordings of open-ended group discussions and one-to-one interviews with some forty-three participants in encounters averaging approximately ninety minutes duration each. The organizations represented in these encounters include various United Nations agencies, the International Committee for the Red Cross, the Palestinian Red Crescent Society, Care International, Médecins San Frontières, Save the Children, and a number of lesser-known humanitarian relief and human rights organizations. I am especially grateful to MEP Dr. Eleni Theocharous of the Cyprus chapter of Médicins Du Monde, as well as staff at the Gaza City headquarters of the Palestinian Red Crescent Society for their invaluable assistance in arranging for the collection of these materials. 
particularly interesting feature of such talk is that speakers attend to the reflexive implications of their own conversational contributions to construct the problematic nature of its assertions in and through the course of the talk's unfolding. Thus, not only do speakers invoke various moral assumptions in explanations of their professional activities, but they also manage their entitlement to comment upon the legitimacy of those activities. In this way, the business of producing an account is reflexively oriented to providing for its own warrant. Where speakers address moral concerns, they also attend to the potential for their talk to be construed as self-serving or otherwise motivated by self-interest. As we will see, laughter and laugh-like features of talk are collaboratively used by speakers to manage the reflexive implications of their own participation through joint efforts to laugh at and laugh with one another. The related collaborative efforts furnish speakers with resources to address different and competing demands for moral accountability, and in particular to circumscribe the extent to which any one demand impinges on its alternatives. More specifically, speakers construct accounts that attend to competing moral considerations, effectively working to substantiate the demands provided for in alternative formulations invoked by their (virtual or actual) interlocutors, while still working to warrant the demands made available in their own, contrasting accounts. This is particularly relevant to the analysis of the interview extracts we consider below where the professional identity that speakers construct in the talk recorded there also furnishes them with entitlement to comment upon its make-up in and through the course of its production in that talk.

\section{Laughter as reflexive engagement}

Let us begin with an extract taken from the transcript of a focus group discussion between different staff members of the United Nations Relief Works Agency (UNRWA). At the time this discussion was recorded, the different participants (Curtis, Owen, and Zina) all worked in various capacities to implement the policies of UNRWA by providing relief and development aid to the community of Palestinian refugees in the Gaza Strip, West Bank and surrounding areas. ${ }^{16}$ Our point of entry in this encounter is at a place where speakers describe their frustration

16. Throughout the transcripts, the individual identities of research participants have been systematically altered with the use of pseudonyms and the deletion of revealing place names in order to ensure conformity with ethical requirements for speaker anonymity (interviewer indicated with the gloss Int). For a complete description of transcription conventions employed here and elsewhere in this paper, see Appendix. 
with carrying out their jobs given that UNRWA's institutional mandate precludes its members from intervening in the political affairs that give rise to the regional conflict. The implicit assumption here is that speaker actions are limited in their effectiveness precisely because of UNRWA's commitment to non-partisanship as a condition of its institutional legitimacy. It is against this background that Curtis addresses the relationship between opposing parties in the Palestinian-Israeli conflict, describing their activities in terms of parity between warring factions (lines 1-25). This contrasts markedly with the immediately subsequent formulation in Zina's more general account, in which some participants of warfare are described as "bigger victims than others" and as being "in worse shape than others" (lines 54, 55). Here the contradictory tension between the assumptions informing these different understandings is managed with an appeal to the Agency's organizational mandate. Significant for our purposes here is the function that laughter has in indexing the tension between these different speaker assumptions in and through the work it does to repair the potential breach in speaker affiliation posed by the introduction of conflicting moral assumptions. ${ }^{17}$

Extract 1. [palis10a, 41:19-43:40]

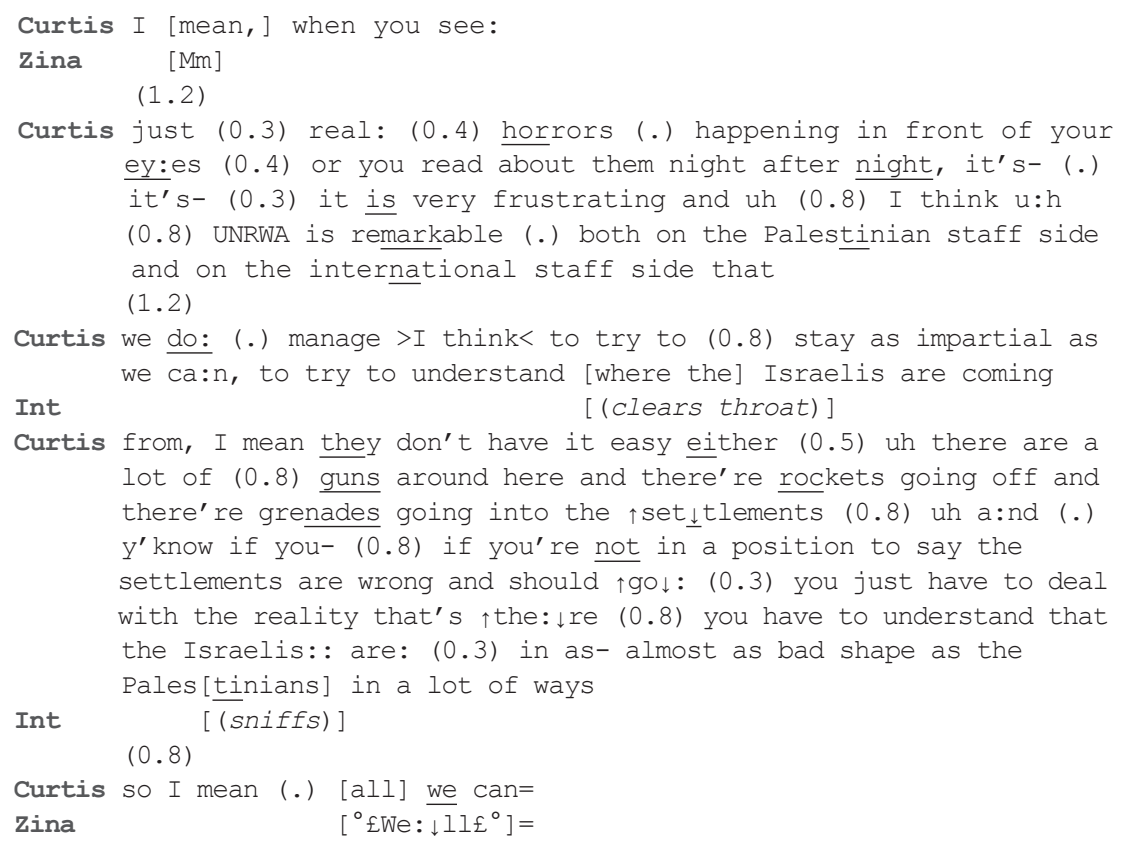

17. For an analysis which is concerned primarily with the rhetorico-responsive formulation of these related demands in this material (as opposed to the focus on laughter taken up here), see McKenzie 2009. 
Curtis $=[$ [do is say- $]$

Zina $=\left[{ }^{\circ}\right.$ uhh hheh hheh $\left.\left.{ }^{\circ}\right]\right]$

(.)

Int ((addressing Zina)) $\uparrow$. hhhh (.) £You don- you don't [look like you believe that£ $\uparrow$. hhh hheh hheh .hh]=

zina [£He's trying to be ve:ry impartial here£]=

Int $\quad=[\mathrm{uh}]=$

Owen $=[£ h h m$ hhm£ $][>\mathrm{hhm}[[\mathrm{hhm} h \mathrm{hm}<]]]$

Int [[huh huh]]

Zina [ [hah hah]]

Curtis $[>$ Well I re- I really< be]lieve that Zina, but I- II think all we can $\uparrow$ do is say (.) 'That's not our jo:b, (.) to settle it' but we strongly believe in what the Secretary General was saying is that violence is not going to settle this, it's just gonna get worse, (0.2) and these people have got to find a

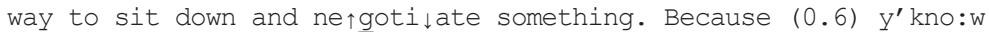
what- >we're seeing< what- what- (.) Tho:mas was seeing, ((alludes to prior discussion)) what we're seeing is $(0.9)$

Curtis the more pressure that's put on these Palestinians ${ }^{\circ}$ th ${ }^{\circ}$ they $^{\prime}$ re not giving up, they're getting more $\uparrow$ radi $\downarrow$ calized. They're getting

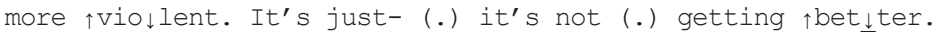
$(1.0)$

Curtis $A:$ nd $u: h$ (1.1)

Zina 'Well ${ }^{\circ}$ that's true and that's where [I differ a $\uparrow$ lit] $\downarrow$ tle bit

Int [ (sniffs) ]

Zina though with uh- the- Curtis- the- >to go from the neutral to the impartial< $u: m{ }^{\circ} \mathrm{uh}^{\circ}{ }^{\circ}$ as in any conflict $\mathrm{u}: \mathrm{h}>$ ih- even being UN:< there are (.) um: (0.2) bigger victims than others. Some $>y^{\prime}$ know< uh (.) $u:{ }^{\circ}: h$ are ${ }^{\circ}$ in- (.) in worse shape than others and I think that $>y^{\prime}$ know $<e^{\prime}$ ve had m- many conflicts where the UN has been involved in peacekeeping (missions) >and) so on< (.) and that's so(h) rt o(h) f wh(h)y I(h) li(h) ke worki(h)ng fin this one. hheh cuz ih we- we ha(h)ve a (h) $n$ excu(h)se: to defe:ndf (.) the one that we are mandated to look after and it gives us a little bit$>$ I mean with-< (.) understanding why some of this: : $u: h$ happens but (.) Israelis use this much t- (.) too $\uparrow$ mul:ch $>y^{\prime}$ know< that uh the security is the excuse for everything that they do, and uh they get away with: quite a lot by that.

In considering how laughter operates here, we can start by focusing on the exchanges that occur at lines 24-29. These involve a rather subtle modulation in the expression of interlocutor affiliation between Curtis and Zina, as well as collaboration between Zina and the interviewer in providing for the relevance of the potentially disaffiliative presumptions made relevant in these different speakers' contributions. Zina's initial well-prefaced remark (delivered with smiley voice articulation and whispered laughter, lines 24-26) signals her dissent with the immediately prior speaker (Cutis), which the interviewer subsequently picks up on in his prompt for Zina to elaborate on the details substantiating the difference in outlook between 
Curtis and herself (lines 28-29). Note how this initial effort is retrospectively targeted with the subsequent laughter, being first described as disaffiliative in the interviewer's remarks (lines 28-29), and then corroborated with laughter in Zina's immediately subsequent uptake, as well as in the collaborative smiley voice interjections on the part of Owen (lines 33), and in the interviewer's and Zina's subsequent, simultaneously articulated dual syllables of light laughter (lines 33, 34). Laughter's work here, of managing the potential threat to reciprocity of perspective, is shared out among parties to the encounter, with the attenuated efforts first broached in Zina's initial contribution extended and shared out among participants through the course of just a few turns-at-talk.

This sharing of laughter is the principle means by which these various parties together work to manage the potential breakdown in mutual affiliation. At the same time, the scale of laughter's intensity can be said to bear a relationship of iconicity in expressing the mitigated extent of affiliation with assertions made by some prior speaker. So, for example, in addressing how one such laugh-like feature - that involving interpolated particles of aspiration (IPAs) - gets deployed in the management of interactional troubles, Potter and Hepburn (2010) suggest that the negotiation of meaning in the use of vocabularies of description entails the withholding or curtailing of affiliation with the full range of inferences that a given word might otherwise be made to have, noting that "one use of IPAs is to show an orientation to such problems while nevertheless not canceling the word's use" (p. 1549). Subtleties in displaying the degree of affiliation simultaneously function as a resource in the ongoing negotiation of meaning throughout the course of the talk's trajectory. In the talk here, Zina attends to the problems that potentially arise in referencing the respective assumptions entailed by her and Curtis's different formulations, glossing these variously with the terms neutral and impartial (lines 53,54). More significantly, in so doing she works to suspend - or rather, transcend - the interactional troubles that disaffiliation otherwise poses. The sort of middle positioned, less-than-fully-affiliative but not-entirely-disaffiliative stance she adopts articulates a third, distinctive basis on which the mutual reciprocity of perspective might be established. Both in the explanatory account with which she seeks to mitigate the differences between Curtis and herself, as well as in the details of that account's formulation (the accompanying laughter and laugh-like features, lines 58-59), Zina both identifies and manages the threat to speaker affiliation otherwise posed by Curtis's immediately prior contribution.

Finally, note that the specific mode of this talk's delivery can also be heard as reflexively oriented to foreclosing the potential for Zina's efforts to be seen as merely directed towards patching up cracks in the edifice of a shared account which that talk is otherwise meant to establish. Thus, the laugh-like features in Zina's talk here not only attend to the difference in assumptions that she and Curtis bring to bear 
in working out the shared understanding that emerges from the mitigation of their respective descriptions, but it also does so in a way that forecloses the potential for her related efforts to be construed as disingenuous. Here laughter and laughlike features in Zina's talk are multivalent in their effect. Their deployment would thus be implicated in the collaborative work they accomplish at different levels of engagement both ideationally (with relevance to mitigation in the substance of the disparate accounts that speakers formulate), and interactionally (with relevance to the collaborative work speakers pursue in producing a joint account of their professional activities as the end objective of the encounter to which they are co-participants, see Lavin and Maynard 2001).

\section{Laughter's as collaborative resource}

So far, we have examined some ways that laughter displays various degrees of intensity in the details of its expression, and suggested that those differences express variations in relative degrees of affiliation on the part of speakers. We also touched on the reflexive aspects of laughter as attendant to the way that efforts at affiliation can themselves be construed to signify the imputation of disingenuousness. Laughter is employed to manage the potential threat to the shared assumption of reciprocity in perspective while reflexively attending to the potential for efforts in doing so to be construed as insincere. To the extent that these tasks are distinct, laughter could be said to be multivalent. Yet these are only different ways of referring to what is essentially the same phenomenon of conversational affiliation. The propositional substance of laughter's targeting (i.e., the retrospective assertion of referential content) is the occasion for interlocutor affiliation, and the shared task of engaging the reflexive implications of laughter's use is itself the situated occasion for further affiliation.

In what follows, I want to consider this aspect of affiliation a bit further by examining an episode of talk in which an alternative and here critical (in the sense attached to moral sanction) account of humanitarian aid gets attended to with the sharing of laughter. The data extract below documents part of a small group discussion with the CEO of a medical relief organization (Clark), and his Executive Assistant (Les). The organization these speakers represent is one that arranges for volunteer doctors and other healthcare professionals to travel on short-term missions to the Palestinian Territories in order to provide lifesaving medical services to the population of refugees living there. The logistic and fundraising efforts involved in organizing such expeditions require full-time employment to which these speakers devote their energies in their professional capacity as aid workers. The extract picks up from an extended turn-at-talk (only the last few lines of which are shown 
here, lines 1-3) in which Clark responds to a prior request by the interviewer to describe the political sensitivities that he (Clark) encounters in the course of carrying out fundraising and public relations activities in the United States. In his extended reply, Clark addresses the question of what justifications answer to accusations of pro-Palestinian partisanship, developing an analogy between Palestinian resistance to Israeli aggression and the American struggle for independence from Great Britain. Following this, in the immediate uptake to the interviewer's elicitation of a turn by Les (lines 8-10), both Clark and Les then corroborate in managing the potential for Clark's prior, extended account to be construed as designed to foreclose a more self-serving, opportunistic account of his motivations.

Extract 2. [palis19b, 2:41-5:39]

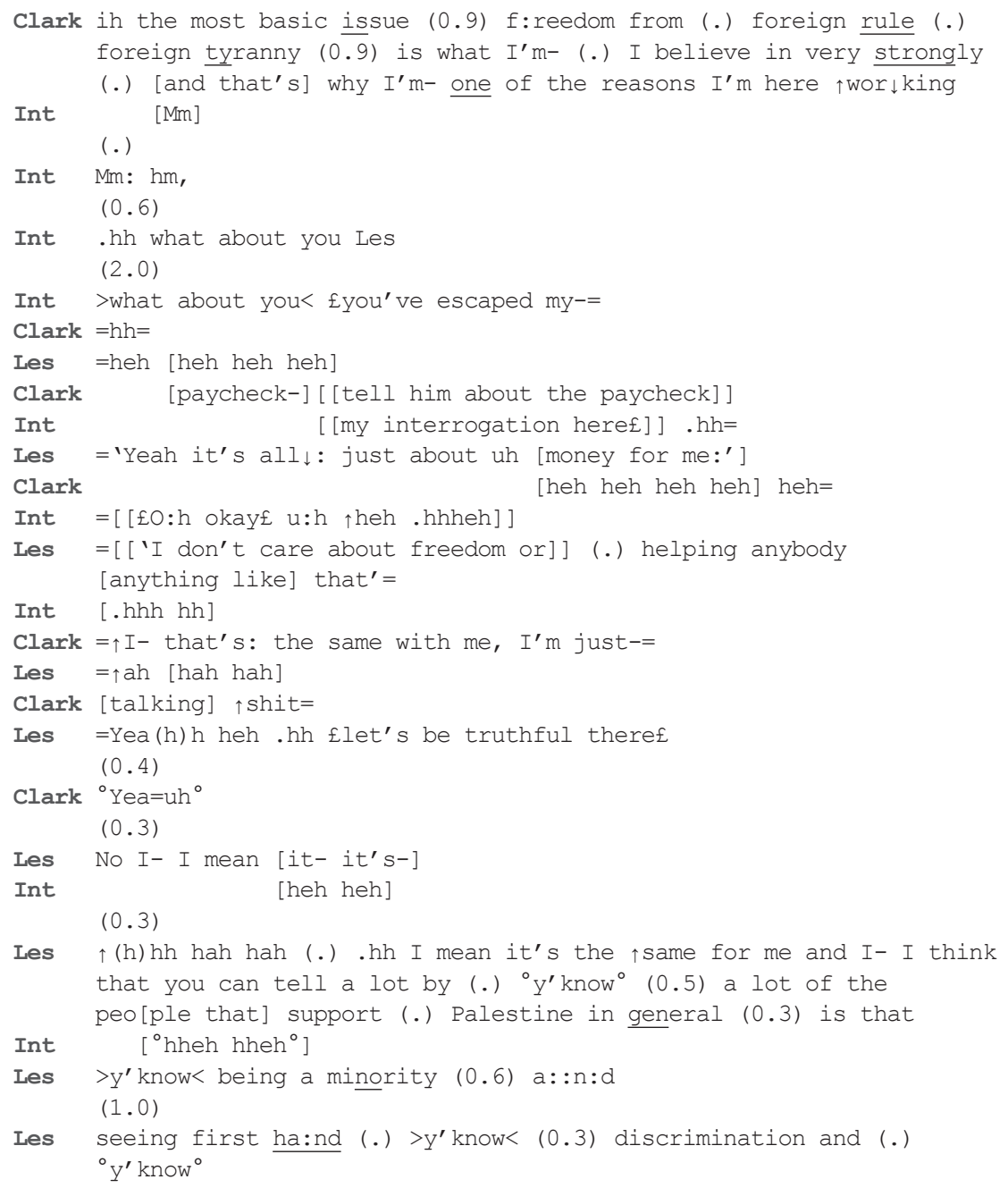




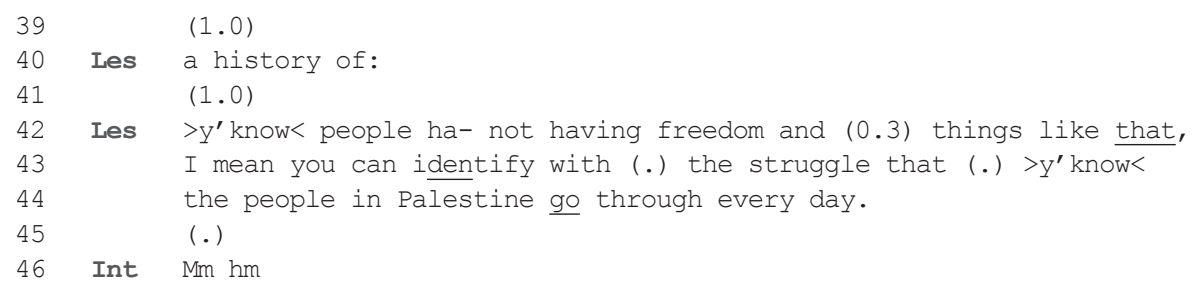

Let us begin here by focusing on the initial series of exchanges in which Clark and Les engage in a short bout of mutual teasing (lines 11-26). As noted elsewhere, teasing is a way for speakers to evaluate some immediately prior turn-at-talk through a reformulation of its significance in a next-turn which construes the prior-turn as overbuilt or excessively disproportionate to the interactional occasion for which it was designed (Drew 1987, Glenn 2010). Basically, this involves a reformulation of what was said in a prior conversational turn. ${ }^{18}$ Indeed, as demonstrated with Clarks's remarks at lines 21-23, that prior turn need not even be that of another speaker, but can have as its target ones own prior talk. Here, Clark directs Les in how to answer the question with which the interviewer had nominated him (Les) as next-speaker (lines 8-10), essentially appropriating Les's projected turn-at-talk in order to initiate a joint undertaking to head-off the critical explanation that his own prior turn might otherwise occasion. In this way, Clark gives voice to the potential for his previous explanation to be construed as disingenuous in and through his recruitment of Les's projected next-turn, so that that turn (Les's appropriated turn) itself is collaboratively brought off as an ironic reformulation of Clark's prior turn. The ironic character of the joint reformulation is initially realized where Les voices his assent in a quotational (or virtual) vocalization with which he distances himself

18. One form such reformulation takes is that of a speaker making explicit the inferential trajectories potentially made available by his or her interlocutor's prior contribution (as where, for example, the description that someone gives of an illness meets with a sardonic diagnosis of impending death: "you probably got at least a week . . before you die"). Another is to treat an interlocutor's prior turn as designed to provide for its own warrant with a formulation that makes explicit the reflexive business which that prior turn could be regarded to serve. Compare this with how the significance of descriptive vocabularies is managed through the use of IPAs, as noted in the previous section. Where there speakers modulate the semantic range of related terms used to describe the relationship between antagonists in the Palestinian-Israeli conflict (so that the proportionality of emphasis is under negotiation), here the alternative interpretation of meaning is undercut. That is, Clark and Les broach no disaffiliation between themselves in the joint account they formulate (even while attending to the potential for third-party dissent), whereas Zina and Curtis open up the potential range of defeasibility to further negotiation. This subtlety in affiliative work is displayed in the expressive degree of laughter that its attendant talk bears, with Clark's and Les's laughter showing a relatively greater degree of expressive intensity than that of Zina and Curtis. 
from the content of his own remarks in the course of their delivery (lines 15, 18-19). This is corroborated in the subsequent laughter and laugh-like features (in both Clark's and the interviewer's uptake, lines 16-17,20), which targets its prior (that is, Les's contribution following Clark's directive) as laughable, and thus non-serious. In this way, not only do Clark and Les (and, to a lesser extent, the interviewer) jointly manage development of the inferential trajectory made available with Clark's prior account, but they also work to limit the potential for that account to be dismissed as disingenuous since the suggestion of vested interest implicating both Clark and Les is formulated with the accompanying laughter through which they disaffiliate themselves from the critical inferences it would otherwise sustain. ${ }^{19}$

Note further that this involves Clark's formulating a disaffiliative stance with the idealized substance of his own prior, extended account as a necessary condition for the work of recruiting Les in the formulation of the stake confessional interpretation from which they both then jointly disaffiliate themselves (lines 15-26; for a discussion of stake confession, see Edwards 1995, 332-335; Potter 1996, 124-132). Clark and Les laugh together at Clark's prior explanation in and through their efforts to laugh with one another about the circumstances of that account's production. Again, note how all of this involves collaboration between the principle speakers. ${ }^{20}$ Without the turn-at-talk in which Clark directs Les in how to respond to the interview question, and further without Les's teasing cooperation in construing Clark's previous turn as duplicitous, the work of foreclosing the potential criticism of their professional activities would not be shared out between them. ${ }^{21}$ All of this

19. Additionally, note how the interviewer's posing of the query here with a smiley voice articulation can be understood as displaying a readiness to engage humorously (' $£$ you've escaped my-my interrogation heref', lines 10-14; see related discussion in Glenn 2003, 66-72). What is not recoverable from the audio-record is whether that laugh-like feature was responsive to visual input (a smile or some other feature of gaze).

20. As an aside, note also that this collaborative activity allows Clark to pass off the work of identifying the target of critique in such a way that he (Clark) not be seen to be laughing at his own joke - an eventuality that might otherwise undermine the efficacy of the work the laughter is designed to accomplish were it to lack corroborative support (see Glenn 2003, 127-141).

21. Another noteworthy feature of this collaborative work involves the joint provision of Les's entitlement to appropriate the account that Clark formulates in view of the legacy of slavery in the United States. Les addresses this in attending to his own "minority" status (see lines 69-75). Thus, the threat to shared perspective devolves here onto the two different speakers' (Clark's and Les's) respective entitlements to invoke an historical analogy as a warrant for the comparison Clark initially draws (lines 15-42). Les expands the range of the analogy to include events of American history beyond those describing the American Revolutionary War. The initial work of Clark to highlight the source of trouble in necessitating shared perspective as attending to individual motivation (line 13) is elegantly transformed in Les's uptake so as to extend the scope of entitlement attending the historical analogy. 
requires close cooperation both to occasion one another's responsive contributions within the conversational junctures where they occur, and to do so in such a way that provides the mutual working up of warrant for their respective accounts.

\section{5. “That's easy for you to say!": Collaborative laughter with virtual self and virtual other}

So far, we have considered talk in multi-party settings where speakers employ laughter to corroborate their respective accounts of professional activities. What we have seen is that speakers collaborate in reworking the significance of some previously formulated explanation in order to manage the threat to interlocutor affiliation that a lack of mutual reciprocity in perspective otherwise poses. Not only does laughter function to reframe the encounter of which it is a part so as to furnish an alternative basis for interlocutor affiliation, but it also functions to identify the source (or ideational substance) of potential disagreement between interlocutors. In addition, we have seen that speakers laugh both at and with one another as a means of managing changes to their respective footing (Glenn 1995), and that the at/with distinction is thereby rendered somewhat ambivalent. Where some speaker makes his or her own prior formulation the target of shared laughter, doing so furnishes the basis for interlocutor affiliation in the activity of jointly ironizing that prior talk. A given speaker can thus laugh both at another speaker's prior formulation as well as laugh with that other in making him- or herself the butt of their own joke, as it were. The ironizing distance that laughter accomplishes thus involves a shared undertaking to render the at/with distinction productively ambivalent in the course of speakers' efforts to manage the affiliation necessary for the joint conduct of their talk.

Now, in what follows, I want to show how this elision or suspension of the at/with distinction compares with what takes place in reported speech where a speaker identifies a laughable in the course of relating an account attributed to some non-present third party. As we shall see, the matter having to do with the relationship between intensity of laughter and the relative degree of affiliation between speakers) is one that features in the variable work of targeting some third party and the recruitment of some then-present interlocutor in effecting the rhetorical implications of a third-party account. More specifically, the degree of speaker affiliation entailed in the shared laughter at (the expense of) some non-present third party is less than that entailed with the shared laughter at some party whose collaborative involvement in the talk necessarily implicates him or her as a condition of his or her own participation. Put more simply, laughing together at someone else is less affiliative than laughing together with someone in laughing at themselves. 
That difference of degree also features in talk where speakers work to mitigate the potential source of disaffiliation entailed in their joint efforts to manage the relevance of competing moral assumptions for the production of a shared account. This is because speaker efforts to affiliate with one another by laughing at the stance attributed to some non-present third party also holds the potential to threaten that affiliation since it highlights the very conceptual contradiction on the basis of which they share their laughter. By aligning with one another at the expense of some third party, speakers necessarily highlight the disaffiliative break with that third party as the basis of their situated affiliation with one another. In the talk we will consider below, we will see that the highlighting of this contradictory feature of the interlocutors' situated projects occasions a shared disaffiliative stance paradoxically formulated in a fashion much like that which we saw in the talk between Clark and Les. The relatively greater degree of reflexive engagement jointly accomplished at this juncture is analogously realized in the relatively greater intensity of laughter attending to this shift in speaker alignment.

Consider the following transcript representing talk with a senior member of the administrative staff of a religiously affiliated organization that delivers relief and development aid around the world. Here, the interviewee (Sonja) recounts the details of a conversation that she reports having had with a colleague from another humanitarian aid organization who, like herself, lives and works in the Palestinian Territories. Of particular significance is what that colleague is said to have made of the fact that Israeli military checkpoints in the Territories may or may not be easily negotiated by the local Palestinian population depending on whether these checkpoints are manned by regular army soldiers or by reservists.

Extract 3. [palis18b, 1:08-2:48]

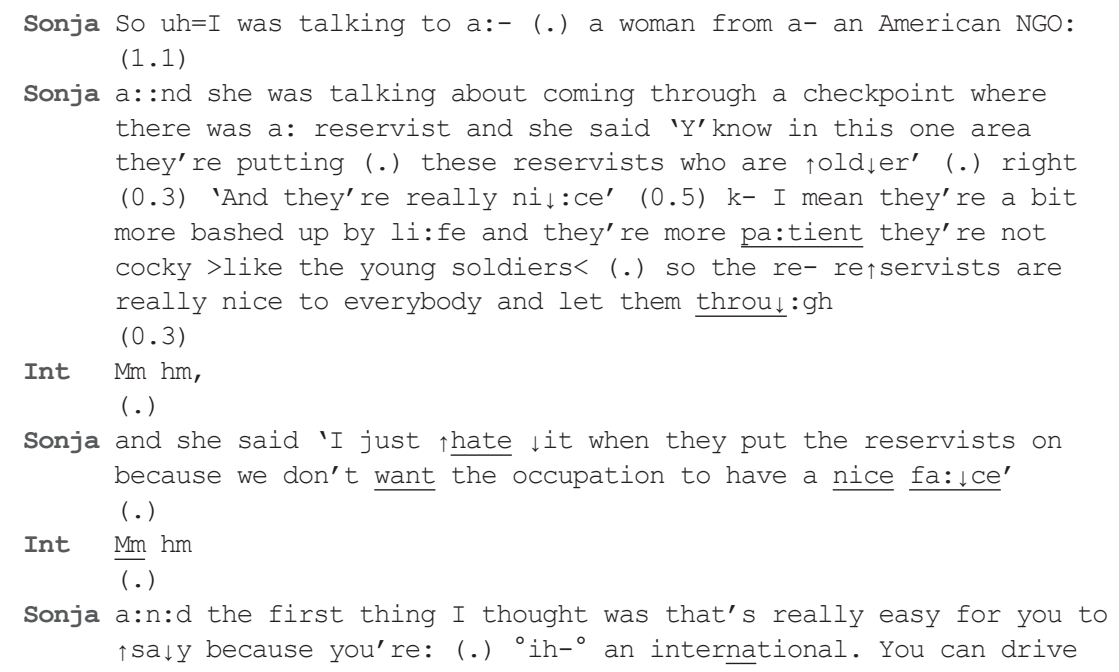


throu $\downarrow$ :gh. You don't have to wait hours and hours, you don't have to sit and worry about your ki: :ds at the checkpoint .hh (.) I would say that (.) $\uparrow a l l$ the people £in those villages $£$ around there are just (.) so reli:eved that there's (.) a nice guy at the checkpoint.

(.)

Int $\mathrm{Mm} \mathrm{hm}, \mathrm{mm} \mathrm{hm,} \mathrm{(.)} \mathrm{mm} \mathrm{hm}$.

(.)

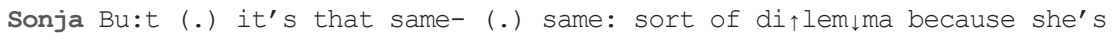
right in a way. (1.0)

Sonja If you have a- a nice per- all the soldiers are ni:ce then the occupation (0.3) has this $n$ - pleasant (1.1)

Sonja $>$ sort of $<\mathrm{FA} \downarrow \mathrm{CE}$

(.)

Int ${ }^{\circ} \mathrm{Mm} \mathrm{hm}, \mathrm{mm} \mathrm{hm},{ }^{\circ}$ (1.0)

Sonja but in the $\uparrow e_{\downarrow}$ :nd (.) it's still the occupation:- (0.2) an illegal occupation (0.8) £of the territor(h) ies. $£=$

Int $\quad=^{\circ}(\mathrm{h}) \mathrm{mm}(\mathrm{h}) \mathrm{mm}^{\circ}=$

Sonja $=$.hhh £So I don't know what you $\uparrow$ do£ wi(h) th tha (h) : $t$ ha=

Int $=(h) \mathrm{mm}(\mathrm{h}) \mathrm{mm}=$

Sonja $=\uparrow \cdot h h$

(.)

Int Well (.) $\mathrm{u}:: \mathrm{h} \mathrm{x}-[\mathrm{xx}-]$

Sonja [£I mean there are times I-£] I've thought everyone should just pack up and go home and (.) ${ }^{\circ}$ th $-^{\circ}$ the only people who can sort this mess out are Palestinians and Israelis (.) bu: $\downarrow: t$ (.) if I leave, the US $\uparrow$ government's not gonna stop giving Israel funds, (.)

Int ${ }^{\circ} \mathrm{Mm} \mathrm{hm},{ }^{\circ}=$

Sonja =so: (.) > $\mathrm{y}^{\prime}$ know it's sort of< I see NGOs as >in a way< trying to balance (.) the sh- US: (.) pouring money into Israel and- money and weapons

(1.0)

Int So if (.) we hear the door slam at four in the morning you:- you may have just [packed your] bags

Sonja [hhh ] ( (blows))

Int [[and left (out of here)]]

Sonja [ [ $\left.\left.{ }^{\circ} \mathrm{xxx}^{\circ}{ }^{\circ} . \mathrm{hh} @\right]\right]$ ] $£ \uparrow \operatorname{may} £ \uparrow h a(h)-\mathrm{ha}(\mathrm{h}) \downarrow$ :ve uh(h) ha [ha ha. hhh ha ha ha $x(\mathrm{~h})]$.hhh .hh £That's right (.) yeahf

Int ['Say goodbye $\downarrow$ : leave a note' you know]

Sonja's talk here recounts a personal narrative relating the practical inefficiencies and detrimental effects of a too principled opposition to Israeli occupation of the Palestinian Territories (see McKenzie 2009, 346-349). As with the talk we considered in Extract 1, wherein speakers work to mitigate the extent that different assumptions entail for an understanding of the events under discussion, so too here Sonja formulates the relationship between: (1) consideration for the practical 
concerns with providing relief to the victims of armed conflict, and (2) the principled opposition to the partisan considerations that occasion the need for relief in the first place (lines 1-24). Note that Sonja does not come down on the side of either perspective, as it were, but rather elaborates on the warrant with which either stance might be ratified (lines 28-39), commenting explicitly upon the suspension of resolution that she claims their equivalent validity would entail (lines 41-55). ${ }^{22}$

For our own purposes, what is of particular interest here is the way in which the laugh-like features attending the reported episode contrasts with what is employed in the subsequent description of projected actions on the part of Sonja (lines 57-63). More specifically, where in the former case Sonja's display of ironizing distance is effected primarily with the use of smiley voice articulation (lines 22, 39, 41,46 ), in the latter instance, smiley voice is employed in combination with laughter and interpolated particles of aspiration (lines 59-63). What distinguishes this latter bit of talk from the former is the work that the interlocutors do to laugh with one another in laughing at the confused and indecisive stance that Sonja attributes to herself in the narrative account contrasting her American colleague and herself. In other words, the narrative formulation creates degrees of distantiation from the events that the anecdote describes. Sonja's remarks formulating her response to the narrative upshot (lines 41-43) yields a further degree of distance, and the shared laughter with which that formulation is then met leads to yet another shared moment of distanciation from the confused ambivalence whose threat to interlocutor affiliation (described of Sonja and here American colleague) is managed for its relevance to the then-present circumstances of the interview. Put differently, Sonja initially claims to have disaffiliated herself from the stance of her American colleague in the setting that her anecdote describes, and this ambivalence itself then furnishes the basis for alignment between herself and the interviewer in laughing with her in laughing at the self of her narrative description.

Here, the occasioning of responsive laughter attending the interviewer's anticipatory description of what Sonja might be expected to do in light of the confusion she describes (lines 57-63) affords both speakers a shared basis for affiliation in the absence of jointly ratified, ideational content (that is, in the absence of an answer to the practical vs. principled debate at issue here). The affiliative orientation occurs at the level of attending to the conflict in shared perspective as itself constituting speakers' mutual business. Speakers address the meta-level implications of their

22. Consider how this way of formulating the different concerns that animate discussion of the relevant issues here works similarly to how speakers undercut the basis with which to arrive at a definitive formulation with talk in juridically consequential settings - what Lynch and Bogen (1996) refer to with the term produced undecidability. 
own prior meta-level formulations at a further level of inclusivity, as it were. ${ }^{23}$ The relative degree of intensity in laughter would thus seem to express degrees of proximity that the orders of disaffiliation are made to have relative to the thenpresent business of the conversational encounter. This is somewhat analogous to how different degrees of clausal transitivity register speaker viewpoint (Hopper and Thompson 1980), or how degrees of an event's reporting (as between first-, second-, third- etc. hand accounts) get deployed to formulate an author's assessment of relative degrees of narrative plausibility of the ideological positioning that an event's description conveys - as, for instance, in Joseph Conrad's Lord Jim, where appeals to Enlightenment ideals of universal justice and equality get indexed in increasingly distanced accounts of reported attribution versus that of the narrator's first-hand depictions of colonial exploitation and opportunism. ${ }^{24}$ Here, the threat to interlocutor affiliation is greater where the implications of some third-party disagreement are explicitly made relevant to the then-current setting of the interview (with its business of jointly formulating documentary evidence) than in an ostensibly straightforward depiction of disaffiliation with some non-present third party. Just as we saw in our examination of Extract 2 where speakers work to manage the implications of their own formulations, so too here Sonja and the interviewer collaboratively work up the laughability of Sonja's prior, immediately-referenced assessment (lines 41-53) as the basis for affiliation in the conduct of the interview's then-immediate business. What makes this especially interesting is the way that subtleties in relative degrees of laugher get deployed to register subtleties in the degree of fragility that shared affiliation undergoes at any given juncture in the course of talk's unfolding development.

\section{Conclusion}

Analysis of the talk presented above has explored the question of how laugher accomplishes interlocutors' situated, ongoing work of maintaining affiliation while managing disparity in the ideational content in their respective accounts. Troubles

23. Addressing the question of reflexivity in interaction, Hilbert $(1992,126)$ cites Alfred Schütz's efforts to identify this aspect as fundamental to the emergence of social order, noting that Schütz treats "intersubjectivity itself as ideational, as part of a subjective orientation, an assumption or presumptive stance on the part of everyday social actors."

24. The variation in laughter and laugh-like features accompanying talk represent a rich domain for further investigation, with preliminary avenues of inquiry potentially exploring the feature of iconicity in laughter (not dissimilar to the investigation of iconicity in syntax, see Haiman 1985; Simone 1994). 
managed in the course of interaction involve attending to the threats to interlocutor affiliation on at least two different levels: (1) that of the reflexive orientation that interlocutors attend to in developing a common stance relative to the significance that their own respective formulations are taken to entail, and (2) that of the ideational content involved where the shared understanding of things like descriptive vocabularies and/or agreement about the significance of events and activities get negotiated in the course of the conversation's development. Especially with regard to the former, we have seen that the potentially troublesome inferences made available in immediately prior contributions are managed in and through interlocutors' joint efforts at provisioning affiliative uptake. For example, in Extract 1 we saw that where staff members of UNRWA attended to potential sources of disagreement between themselves relative to their varied depictions of events in the Palestinian-Israeli conflict, that a threat to the shared ideational basis for affiliation was dealt with through the negotiation of meaning attached to the vocabulary of description (in relation to the words "impartial" and "neutral"). There, speakers did not so much come to an agreement about how given terms were to be understood as much as they devised a shared project of negotiating the relevance of alternative vocabularies as the basis upon which to proceed in their talk.

Similarly, in the talk from Extract 2, speakers jointly devised an ironic reading of one of their own immediately prior, extended turns-at-talk, and in this way managed the threat that the related critique would otherwise entail for the group's affiliative coherence in developing a shared account. The detached (non-serious) warranting of a dissenting, critical account itself formed the basis for speaker affiliation. The conversation's sequential organization was maneuvered in such a way as to establish the jocose discrediting of the prior explanation (with Clark's appropriation of the turn to which Les had been nominated, line 13). That stance itself then furnished the basis for further speaker affiliation. An interesting aspect of this interactional work was that the speakers were not only able to collaborate in shoring up their endorsement of the initial account (in which Clark compares the Palestinian struggle with the American Revolution), but they were also able to do so in a way that set forth the specific terms of a critical counter-formulation. This is not simply a case of identifying some point of disagreement that potentially poses a threat to interlocutor affiliation. It is also a case of undercutting the relevance of that threat's ideational content to and for the specific understanding that is to emerge from the encounter.

Finally, in examining the talk recorded in Extract 3, we saw a rather more complicated bit of discursive work in which the interviewee (Sonja) used reported speech to highlight a difference of opinion between herself and her American colleague on the question of whether to adopt either a principled or a practical stance in relation to the Israeli occupation. That difference of opinion was then taken as 
the object of joint reflection by which Sonja and the interviewer were able to gain a different level of footing as a way to establish mutual alignment. In addition, that shift allowed Sonja to display what it is it that she took the interview encounter to have as its overall purpose. Here, her talk was not so much directed at accounting for the legitimacy of aid work as it was at describing the disparity in accounts shared among the community of her professional colleagues. Sonja employed laughter as a way of affiliating herself with the interviewer's role as outside investigator (“'hhh $£$ So I don’t know what you $\underline{\text { do }}$ E wi(h)th tha(h):t ha”, line 41). Note that this involves deploying laughter is a way that is potentially ambiguous, since the interviewer's own laughter could variably be heard as violating the very neutrality constraints with which the encounter's different parties (interviewer and interviewee) otherwise accomplish their respective entitlements and obligations (see Lavin and Maynard 1998, and related discussion in Glenn 2003, 65). This would account for Sonja's use of smiley voice articulation: the laugh-like, but not-fully-laughing quality of her delivery furnishes the basis for affiliation between interviewer and interviewee, but in a way that need not be taken as suggesting the interviewer has abandoned the stance of (assumed) neutrality displayed in non-laughing uptake. In addition, both the interviewer's contributions and Sonja's response (lines 57-63) sustain the collaborative endorsement of roles: the interviewer displays his hearing of Sonja's talk as inviting affiliative laughter with his reference to the upshot of its ideational content rather than with overt laughter. Note that this differs from the multi-party interview talk represented in Extract 2 where there, affiliation through laughter is less ambiguous given that the sharing of laughter is primarily between the interviewees (Clark and Les) in pursuit of their collaborative work rather than between interviewee and interviewer as would be the case in two-party talk. Here, speakers jointly attend both to the affiliative work of interaction, as well as the work of providing for their respective roles in the interview encounter. Sonja's laughter is not disaffiliative of the interviewer's comments (since they are accompanied by explicit agreement, "EI $\uparrow$ may£ $\uparrow h a(h)-h a(h) \downarrow$ :ve uh(h) ha ha ha .hhh ha ha ha $\mathrm{x}(\mathrm{h})$ .hhh .hh $£$ That's right (.) yeah£”, lines 61-62), but affiliative of the work he undertakes as research investigator. By responding to his immediately prior remarks (in lines 57-60) as laughable, Sonja attends to the affiliative work that her own prior, smiley-voiced descriptions invite the interviewer to corroborate, while doing so in a way that manages the potential for the interviewer to be seen as non-neutral.

The three episodes of talk we have considered above thus appear to be far more complicated than an initial problematic attending to the management of threats to shared perspective might suggest. The situated work of providing the warrant for an account and of recruiting others in that task means that the use of laughter and laugh-like features of talk is both ambivalent and complex. This is because whatever accounts interlocutors formulate cannot but bear reflexively upon the 
circumstances of their production (and likewise, attention to the reflexive implications of interaction's developing production cannot but hold implications for the ideational content that the related formulations bear). I have attempted to indicate some of the complicated ways that laughter and laugh-like features are made to operate in attending to interlocutor affiliation in multiple modes as between the interactional and ideational. The implication involved is that the distinction describes an analytic heuristic rather than an ontological difference. Speakers not only manage potential threats to the semblance of shared understanding, but identify for one another those points of conceptual difference that require mitigation in order to arrive at a corroborative account. In this sense, speakers work both to warrant their shared entitlement in the setting at hand, as well as to attend to the potential threat to interlocutor affiliation (Heritage 2012a, 2012b, 2013). The points of interlocutor disagreement feature as a practical problem to the conduct of interaction, and speakers work collaboratively to unify the interactional space in which their shared explanations are negotiated.

\section{Acknowledgements}

I wish to thank anonymous reviewers for their invaluable suggestions for improvement to prior versions of this article.

\section{References}

Ashmore, Malcolm. 1989. The Reflexive Thesis: Wrighting Sociology of Scientific Knowledge. Chicago, IL: University of Chicago Press.

Ashmore, Malcom, and Darren Reed. 2000. "Innocence and Nostalgia in Conversation Analysis: The Dynamic Relations of Tape and Transcript." Forum Qualitative Sozialforschung/Forum: Qualitative Social Research 1 (3).

Ashmore, Malcolm, Katie MacMillan, and Steven D. Brown. 2004. "It's a Scream: Professional Hearing and Tape Fetishism." Journal of Pragmatics 36: 349-374.

doi: 10.1016/S0378-2166(03)00005-5

Attardo, Salvatore. 1997. “The Semantic Foundations of Cognitive Theories of Humor." Humor 10 (4): 395-420. doi: 10.1515/humr.1997.10.4.395

Attardo, Salvatore. 2002. "Humor and Irony in Interaction: From Mode Adoption to Failure of Detection." In Say Not to Say: New Perspectives on Miscommunication, ed. by Luigi Anolli, Rita Cicei, and Giuseppe Riva, 159-180. Amsterdam: IOS Press.

Austin, Paddy. 1990. "Politeness Revisited - The Dark Side." In New Zealand Ways of Speaking English, ed. by Allan Bell and Janet Holmes, 277-293. Clevedon, Avon: Multilingual Matters. Bergson, Henri, Cloudesley Shovell Henry Brereton, and Fred Rothwell. 1914. Laughter: An Essay on the Meaning of the Comic. London: Macmillan.

Billig, Michael. 2005. Laughter and Ridicule: Towards a Social Critique of Humour. London: Sage. 
Billig, Michael, Susan Condor, Derek Edwards, Mike Gane, David Middleton, and Alan Radley. 1988. Ideological Dilemmas: A Social Psychology of Everyday Thinking. London: Sage.

Boden, Deidre. 1990. “The World as it Happens: Ethnomethodology and Conversation Analysis.” In Frontiers of Social Theory: The New Synthesis, ed. by George Ritzer, 185-213. New York: Columbia University Press.

Brown, Penelope, and Stephen Levinson. 1987. Politeness: Some Universals in Language Usage. Cambridge: Cambridge University Press.

Chapman, Anthony, and Hugh Foot. (eds.). 1976. Humour and Laughter: Theory, Research and Applications. London: John Wiley.

Collins, Randall. 1981. "On the Microfoundations of Macrosociology." American Journal of Sociology 86 (5): 984-1014. doi:10.1086/227351

Collins, Randall. 1987. "Interaction Ritual Chains, Power, and Property: The Micro-Macro Connection as an Empirically Based Theoretical Problem.” In The Micro-Macro Link, ed. by Jeffrey C. Alexander, Bernhard Giesen, Richard Münch, and Neil J. Smelser, 193-206. Berkeley, CA: University of California Press.

Drew, Paul. 1987. "Po-Faced Receipts of Teases." Linguistics 25: 219-253. doi: 10.1515/ling.1987.25.1.219

Du Bois, John W. 1991. “Transcription Design Principles for Spoken Discourse Research.” Pragmatics 1: 71-106. doi:10.1075/prag.1.1.04boi

Du Bois, John W., Stephan Schuetze-Coburn, Susanna Cumming, and Danae Paolino. 1993. “Outline of Discourse Transcription." In Talking Data: Transcription and Coding in Discourse Research, ed. by Jane A. Edwards, and Martin D. Lampert, 45-89. Hillsdale, N.J.: Lawrence Erlbaum Associates.

Edwards, Derek. 1995. "Two to Tango: Script Formulations, Dispositions, and Rhetorical Symmetry in Relationship Troubles Talk." Research on Language and Social Interaction 28 (4): 319-350. doi:10.1207/s15327973rlsi2804_1

Edwards, Derek. 2005. "Moaning, Whinging and Laughing: The Subjective Side of Complaints." Discourse Studies 7 (1): 5-29. doi:10.1177/1461445605048765

Foucault, Michel. 1980. “The Eye of Power.” In Knowledge/Power: Selected Interviews \& Other Writings, 1972-1977, ed. by Colin Gordon, 146-165. New York: Pantheon Books.

Freud, Sigmund. 1938. "Wit and Its Relation to the Unconscious." In The Basic Writings of Sigmund Freud, 631-805. New York: Modern Library.

Garfinkel, Harold. 1967. Studies in Ethnomethodology. Englewood Cliffs, CA: Prentice-Hall.

Garfinkel, Harold. 1974. "Origins of the Term 'Ethnomethodology"' In Ethnomethodology: Selected Readings, ed. by Roy Turner, 15-18. Harmondsworth: Penguin Education.

Garfinkel, Harold. 1991. "Respecification: Evidence for Locally Produced, Naturally Accountable Phenomena of Order*, Logic, Reason, Meaning, Method, etc., in and as of the Essential Haecceity of Immortal Ordinary Society, (I) - An Announcement of Studies." In Ethnomethodology and the Human Sciences, ed. by Graham Button, 10-19. Cambridge: Cambridge University Press. doi:10.1017/CBO9780511611827.003

Garfinkel, Harold. 1996. “Ethnomethodology’s Program.” Social Psychology Quarterly 59 (1): 5-21. doi: $10.2307 / 2787116$

Garfinkel, Harold. 2002. Ethnomethodology's Program: Working out Durkheim's Aphorism., ed. \& introd. by Anne Warfield Rawls. Lanham, MD: Rowman \& Littlefield Publishers.

Garfinkel, Harold. 2006. Seeing Sociologically: The Routine Grounds of Social Action. Boulder, CO and London: Paradigm Publishers. 
Garfinkel, Harold. 2007. "Four Relations between Literatures of the Social Scientific Movement and their Specific Ethnomethodological Alternate." In Orders of Ordinary Action: Respecifying Sociological Knowledge, ed. by Stephen Hester and David Francis, 13-29. Aldershot, Hampshire and Burlington, VT: Ashgate.

Garfinkel, Harold, and Harvey Sacks. 1970. "On the Formal Structures of Practical Action.” In Theoretical Sociology, ed. by John C. McKinney, and Edward A. Tiryakian, 338-366. New York: Appleton-Century-Crofts.

Garfinkel, Harold, and D. Lawrence Wieder. 1992. "Two Incommensurable, Asymmetrically Alternate Technologies of Social Analysis.” In Text in Context: Contributions to Ethnomethodology, ed. by Graham Watson, and Robert M. Seller, 175-206. London: Sage.

Giddens, Anthony. 1984. The Constitution of Society: Outline of the Theory of Structuration. Cambridge: Polity Press.

Glenn, Phillip. 1995. "Laughing at and Laughing with: Negotiation of Participant Alignments through Conversational Laughter." In Situated Order: Studies in the Social Organization of Talk and Embodied Activities, ed. by Paul ten Have, and George Psathas, 43-56. Landham, MD: University Press of America.

Glenn, Phillip. 2003. Laughter in Interaction. Cambridge: Cambridge University Press. doi: $10.1017 / C B O 9780511519888$

Glenn, Phillip. 2010. "Interviewer Laughs: Shared Laughter and Asymmetries in Employment Interviews." Journal of Pragmatics 42 (6): 1485-1498. doi:10.1016/j.pragma.2010.01.009

Graham, Elizabeth E., Michael J. Papa, and Gordon P. Brooks. 1992. "Functions of Humour in Conversation: Conceptualization and Measurement." Western Journal of Communication 56 (2): 161-183. doi:10.1080/10570319209374409

Haakana, Markku. 2001. "Laughter as a Participant's Resource: Dealing with Delicate Aspects of Medical Interaction.” Text 21: 187-219.

Haakana, Markku. 2002. "Laughter in Medical Interaction: From Quantification to Analysis, and Back." Journal of Sociolinguistics 6: 207-235. doi:10.1111/1467-9481.00185

Haiman, John (ed.). 1985. Iconicity in Syntax. Amsterdam: John Benjamins. doi:10.1075/tsl.6

Heidegger, Martin. 1993. "On the Essence of Truth." In Basic Writings: From Time and Being (1927) to The Task of Thinking (1964), revised and expanded edition, ed. by David Ferrel Krell, 115-138. London: Routledge.

Heritage, John. 1984. Garfinkel and Ethnomethodology. Cambridge, MA: Polity Press.

Heritage, John. 2004. "Conversation Analysis and Institutional Talk." In Handbook of Language and Social Interaction, ed. by Kristine L. Fitch and Robert E. Sanders, 103-147. New York and London: Psychology Press.

Heritage, John. 2012a. "Epistemics in Action: Action Formation and Territories of Knowledge." Research on Language and Social Interaction 45 (1): 1-29. doi:10.1080/08351813.2012.646684

Heritage, John. 2012b. “The Epistemic Engine: Sequence Organization and Territories of Knowledge.” Research on Language and Social Interaction 45 (1): 30-52. doi:10.1080/08351813.2012.646685

Heritage, John. 2013. "Action Formation and its Epistemic (and Other) Backgrounds." Discourse Studies 15 (5): 551-578. doi: 10.1177/1461445613501449

Hilbert, Richard A. 1992. The Classical Roots of Ethnomethodology: Durkheim, Weber, and Garfinkel. Chapel Hill, NC and London: University of North Carolina Press.

Hilbert, Richard A. 2009. "Ethnomethodology and Social Theory." In The New Blackwell Companion to Social Theory, ed. by Bryan S. Turner, 159-178. Chichester, West Sussex: Wiley-Blackwell. doi:10.1002/9781444304992.ch8 
Holmes, Janet. 2000. "Politeness, Power and Provocation: How Humour Functions in the Workplace.” Discourse Studies 2 (2): 159-185. doi:10.1177/1461445600002002002

Holmes, Janet. 2006. "Sharing a Laugh: Pragmatic Aspects of Humor and Gender in the Workplace." Journal of Pragmatics 38: 26-50. doi:10.1016/j.pragma.2005.06.007

Holmes, Janet, and Meredith Marra. 2002. "Having a Laugh at Work: How Humour Contributes to Workplace Culture." Journal of Pragmatics 34: 1683-1710. doi:10.1016/S0378-2166(02)00032-2 Holt, Elizabeth. 2010. “The Last Laugh: Shared Laughter and Topic Termination.” Journal of Pragmatics 42 (6): 1513-1525. doi:10.1016/j.pragma.2010.01.011

Holt, Elizabeth. 2011. "On the Nature of "Laughables": Laughter as a Response to Overdone Figurative Phrases.” Pragmatics 21 (3): 393-410. doi:10.1075/prag.21.3.05hol

Hopper, Paul J., and Sandra A. Thompson. 1980. “Transitivity in Grammar and Discourse.” Language 56 (2): 251-299. doi:10.1353/lan.1980.0017

Horton-Salway, Mary. 1998. Mind and Body in the Discursive Construction of M.E.: A Struggle for Authorship of an Illness. Unpublished Ph.D. thesis, Loughborough University.

Hutchby, Ian, and Robin Wooffitt. 2008. Conversation Analysis. Cambridge and Malden, MA: Polity.

Hutchinson, Phil, Rupert Read, and Wes Sharrock. 2008. There is no Such Thing as a Social Science: In Defense of Peter Winch. Aldershot, Hampshire and Burlington, VT: Ashgate.

Jefferson, Gail. 1979. "A Technique for Inviting Laughter and its Subsequent Acceptance Declination." In Everyday Language: Studies in Ethnomethodology, ed. by George Psathas. New York: Irvington.

Jefferson, Gail. 1984. "On the Organization of Laughter in Talk about Troubles." In Structures of Social Action: Studies in Conversation Analysis, ed. by J. Maxwell Atkinson, and John Heritage, 346-369. Cambridge: Cambridge University Press.

Jefferson, Gail. 1985. “An Exercise in the Transcription and Analysis of Laughter." In Handbook of Discourse Analysis, Vol. 3: Discourse and Dialogue, ed. by Teun A. van Dijk, 25-34. London: Academic Press.

Jefferson, Gail. 2004. “A Note on Laughter in 'Male-Female' Interaction.” Discourse Studies 6: 117-133. doi: 10.1177/1461445604039445

Jefferson, Gail, Harvey Sacks, and Emanuel Schegloff. 1987. "Notes on Laughter in Pursuit of Intimacy." In Talk and Social Organisation, ed. by Graham Button, and John R. E. Lee, 152205. Clevedon, England: Multilingual Matters.

Jha, Prem, and Eric Hobsbawm. 2006. The Twilight of the Nation State: Globalisation, Chaos and War. London and Ann Arbor, MI: Pluto Press.

Kaldor, Mary. 1999. New and Old Wars: Organized Violence in a Global Era. Cambridge: Polity Press.

Keyton, Joann, and Stephenson J. Beck. 2010. "Examining Laughter Functionality in Jury Deliberations.” Small Group Research 41 (4): 386-407. doi:10.1177/1046496410366311

Koestler, Arthur. 1964. The Act of Creation: A Study of the Conscious and Unconscious in Science and Art. London: Hutchinson.

Lavin, Danielle, and Douglas W. Maynard. 2001. "Standardization vs. Rapport: Respondent Laughter and Interviewer Reaction during Telephone Surveys." American Sociological Review 66 (3): 453-479. doi: $10.2307 / 3088888$

Lampert, Martin D., and Susan M. Ervin-Tripp. 2006. "Risky Laughter: Teasing and Self-Directed Joking among Male and Female Friends." Journal of Pragmatics 38: 51-72.

doi: 10.1016/j.pragma.2005.06.004 
Liberman, Kenneth. 2007. Husserl's Criticism of Reason: With Ethnomethodological Specifications. Lanham, MD: Lexington Books.

Lynch, Michael. 2012. "Revisiting the Cultural Dope." Human Studies 35 (2): 223-233. doi: 10.1007/s10746-012-9227-Z

Lynch, Michael, and David Bogen. 1996. The Spectacle of History: Speech, Text, and Memory at the Iran-Contra Hearings. Durham, NC: Duke University Press.

Mair, Michael, Christian Greiffenhagen, and Wes W. Sharrock. 2015. "Statistical Practice: Putting Society on Display." Theory, Culture \& Society 33 (3): 51-77.

Malešević, Siniša. 2010. The Sociology of War and Violence. Cambridge: Cambridge University Press. doi:10.1017/CBO9780511777752

Maynard, Douglas W., and John Heritage. 2005. "Conversation Analysis, Doctor-Patient Interaction and Medical Communication." Medical Education 39 (4): 428-435. doi: 10.1111/j.1365-2929.2005.02111.x

McKenzie, Kevin. 2009. “The Humanitarian Imperative under Fire." Journal of Language and Politics 8 (3): 333-358. doi:10.1075/jlp.8.3.01mck

McKenzie, Kevin. 2011. "Structure and Agency in Scholarly Formulations of Racism." Human Studies 34: 67-92. doi:10.1007/s10746-011-9176-y

Mehan, Hugh, and Houston Wood. 1975. The Reality of Ethnomethodology. New York: John Wiley \& Sons.

Mulkay, Michael. 1988. On Humour. Cambridge: Polity.

Pazzini, Franca. 1991. "Communication Hierarchies in Humour: Gender Differences in the Obstetrical/Gynaecological Setting.” Discourse \& Society 2 (4): 477-488. doi: $10.1177 / 0957926591002004008$

Pollner, Melvin. 1974. "Mundane Reasoning." Philosophy of the Social Sciences 4: 35-54. doi: $10.1177 / 004839317400400103$

Pollner, Melvin. 1987. Mundane Reason: Reality in Everyday and Sociological Discourse. Durham, NC: Duke University Press.

Potter, Jonathan. 1996. Representing Reality: Discourse, Rhetoric and Social Construction. London: Sage. doi:10.4135/9781446222119

Potter, Jonathan. 1998. "Cognition as Context (Whose Cognition?)." Research on Language and Social Interaction 31 (1): 29-44. doi:10.1207/s15327973rlsi3101_2

Potter, Jonathan, and Alexa Hepburn. 2010. "Putting Aspiration into Words: 'Laugh Particles', Managing Descriptive Trouble and Modulating Action.” Journal of Pragmatics 42 (6): 15431555. doi:10.1016/j.pragma.2009.10.003

Rawls, Anne Warfield. 1989. "Language, Self and Social Order: A Reformulation of Goffman and Sacks." Human Studies 12 (1/2): 147-172. doi:10.1007/BFoo142843

Rieff, David. 2002. A Bed for the Night: Humanitarianism in Crisis. London: Vintage.

Ruiz-Gurillo, Leonor, and M. Belén Alvarado-Ortega (eds.). 2013. Irony and Humor: From Pragmatics to Discourse. Amsterdam and Philadelphia, PA: John Benjamins. doi: $10.1075 /$ pbns.231

Sacks, Harvey, Emanuel A. Schegloff, and Gail Jefferson. 1974. "A Simplest Systematics for the Organization of Turn-Taking for Conversation." Language 50 (4): 696-735. doi: 10.1353/lan.1974.0010

Schegloff, Emanuel A. 1992. “On Talk and its Institutional Occasions.” In Talk at Work: Interaction in Institutional Settings, ed. by Paul Drew and John Heritage, 101-134. Cambridge: Cambridge University Press. 
Schegloff, Emanuel A. 1997. “Whose Text? Whose Context?” Discourse \& Society 8 (2): 165-187. doi: 10.1177/0957926597008002002

Schütz, Alfred. 1967. The Phenomenology of the Social World. Chicago, IL: Northwestern University Press.

Sharrock, Wes. 1974. “On Owning Knowledge.” In Ethnomethodology: Selected Readings, ed. by Roy Turner, 45-53. Harmondsworth: Penguin Education.

Sharrock, Wes. 2004. "What Garfinkel Makes of Schutz: The Past, Present and Future of an Alternate, Asymmetric and Incommensurable Approach to Sociology." Theory \& Science. Available at http://theoryandscience.icapp.org/content/vol5.1/sharrock.html.

Sharrock, Wes, and Robert J. Anderson. 1987. “The Definition of Alternatives: Some Sources of Confusion in Interdisciplinary Discussion." In Talk and Social Organisation, ed. by Graham Button, and Robert E. Lee, 290-321. Philadelphia, PA: Multilingual Matters Ltd.

Simone, Raffaela (ed.). 1994. Iconicity in Language. Amsterdam: John Benjamins.

Steiner, H. J., and P. Alston. 2000. International Human Rights in Context: Law, Politics, Morals, second edition. Oxford: Oxford University Press.

Strengers, Isabelle. 2011. Thinking with Whitehead: A Free and Wild Creation of Concepts, trans. by Michael Chase. Cambridge MA and London: Harvard University Press.

Tracy, Karen, and Nikolas Coupland. 1990. "Multiple Goals in Discourse: An Overview of Issues." Journal of Language and Social Psychology 9 (1-2): 1-13. doi:10.1177/0261927X9091001

Truong, Khiet P., and David A. van Leeuwen. 2007. "Automatic Discrimination between Laughter and Speech.” Speech Communication 49: 144-158. doi:10.1016/j.specom.2007.01.001

Van Dijk, Teun A. 1998. Ideology: A Multidisciplinary Approach. London and Thousand Oaks, CA: Sage.

Van Dijk, Teun A. 2006. "Discourse, Context and Cognition.” Discourse Studies 8 (1): 159-177. doi: $10.1177 / 1461445606059565$

Wagner, Johannes, and Monika Vöge (eds.). 2010. “Laughter in Interaction.” Journal of Pragmatics 42 (6): 1469-1576.

Watson, Rod. 1998. "Ethnomethodology, Consciousness and Self." Journal of Consciousness Studies 5 (2): 202-223.

Whalen, Marylin R., and Don H. Zimmerman. 1990. "Describing Trouble: Practical Epistemology in Citizen Calls to the Police." Language in Society 19 (4): 465-492.

doi: 10.1017/So047404500014779

Wilson, Thomas P. 2003. "Garfinkels' Radical Program.” Research on Language and Social Interaction 36 (4): 487-494. doi:10.1207/S15327973RLSI3604_8

Winch, Peter. 1958. The Idea of a Social Science. London: Routledge \& Kegan Paul.

Winick, Charles. 1976. “The Social Contexts of Humor." Journal of Communication 26 (3): 124128. doi:10.1111/j.1460-2466.1976.tbo1915.x

Žižek, Slavoj. 2011. "With Hegel beyond Hegel." Criticism 53 (2): 295-313.

doi: 10.1353/crt.2011.0011 


\section{Appendix}

\section{Transcription conventions}

The transcription of talk that appears above is based on the well-known set of conventions initially developed by Gail Jefferson (1985, see also Sacks et al., 1974), and extended by John Du Bois and his colleagues $(1991,1993)$. Included among these conventions in the extracts above are the following:

full stop indicates completion intonation

comma indicates continuing intonation

underlining indicates additional stress

prolongation of sound indicated with colon

false starts indicated with a dash followed by a single space

voiceless articulation indicated with ${ }^{\circ}$ symbol

talk delivered with an increase in speed indicated with inward pointing arrows

all caps indicate increase in volume

quotation as a presentational feature indicated with single quote up/down arrows precede marked rise or fall in intonation equal sign indicates no space between two speaker turns at talk or in single speaker articulation

untimed pause indicated by a full stop enclosed in parentheses timed pause in talk indicated to tenth of a second

speaker overlap indicated with square brackets (or double square brackets to disambiguate)

voiceless articulation (whisper) indicated with diacritic surrounding effected talk

audible inbreath of varying length

audible outbreath of varying length

description of articulatory detail in single parentheses, italicized

editorial comment indicated with remark in double parentheses, italicized

syllables of laughter indicating degrees of openness

in-breath coarticulated with laughter (chortle)

out-breath coarticulated with laughter

interpolated particles of aspiration (IPAs) inserted into words, indicated with $(\mathrm{h})$

smiley voice over stretch of talk indicated with $£$ can understand that.

where the Israelis are coming from, is the excuse for everything

a::n:d a history of:

and I-I think that you can tell

${ }^{\circ} \mathrm{y}^{\prime} \mathrm{know}^{\circ}$

$>$ what about you<

pleasant $>$ sort of $<$ FA $\downarrow$ CE

'helping anybody anything like that' going into the $\uparrow$ set $\downarrow$ tlements

Int ${ }^{\circ} \mathrm{Mm} \mathrm{hm},{ }^{\circ}=$

Sonja $=$ so::

${ }^{\circ} Y e a=u h^{\circ}$

(.)

Int $[\mathrm{Mm}]$

Clark [and that's] why I'm-

Curtis [[do is say-]]

Zina [[ ${ }^{\circ}$ uhh hheh hheh $\left.\left.{ }^{\circ}\right]\right]$

$\mathrm{Mm} \mathrm{hm} \mathrm{mm}{ }^{\circ} \mathrm{hm}^{\circ}$

.hh .hhh

hh hhhh

hhhh (blows)

((addressing Zina $))$

heh hah

.hhheh

hhheh

and that's so(h)rt o(h)f wh(h)y I(h)

li(h)ke worki(h)ng

£you've escaped my-my

interrogation heref

\section{Author's address}

Kevin McKenzie

mckenziekg@gmail.com 
